\title{
Heat Treatment Development for the TREAT LEU Fuel Zr-alloy Cladding via Time- Temperature Diagrams
}

Clemente Parga

June 2018

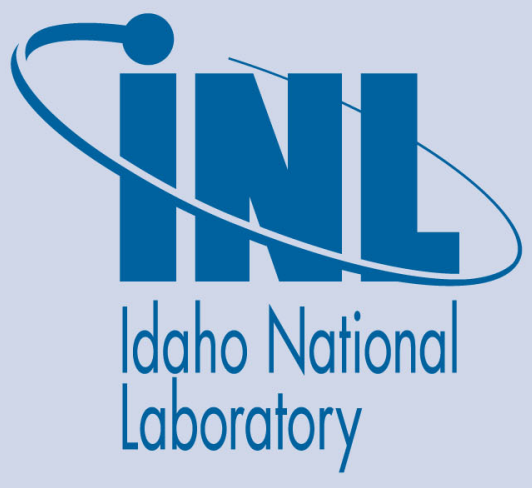

The INL is a U.S. Department of Energy National Laboratory operated by Battelle Energy Alliance 


\title{
Heat Treatment Development for the TREAT LEU Fuel Zr-alloy Cladding via Time-Temperature Diagrams
}

\author{
Clemente Parga
}

June 2018

Idaho National Laboratory Idaho Falls, Idaho 83415

http://www.inl.gov

Prepared for the

U.S. Department of Energy

Under DOE Idaho Operations Office

Contract DE-AC07-05ID14517 
Review and Development Plan

Project No. 31772

\section{Heat Treatment Development for the TREAT LEU Fuel Zr-alloy Cladding via Time-temperature Diagrams}

Clemente J. Parga

June 2018

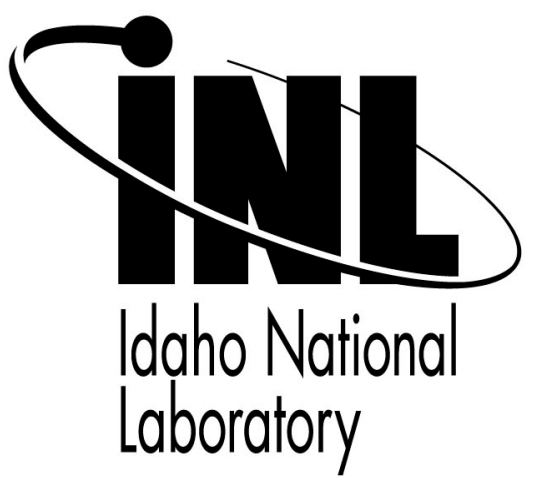

The INL is a U.S. Department of Energy National Laboratory operated by Battelle Energy Alliance. 
INTENTIONALLY BLANK 
Idaho National Laboratory

\begin{tabular}{c|lll|} 
HEAT TREATMENT DEVELOPMENT & Identifier: & PLN-5403 \\
FOR THE TREAT LEU FUEL & Revision: & 0 & \\
ZR-ALLOY CLADDING VIA & Effective Date: & $07 / 02 / 2018$ & Page: iii of vi \\
TIME-TEMPERATURE DIAGRAMS & & & \\
\hline
\end{tabular}

\section{REVISION LOG}

\begin{tabular}{|c|c|c|c|}
\hline Rev. & Date & Affected Pages & Revision Description \\
\hline 0 & $07 / 02 / 2018$ & All & See eCR 651498. New Issue. \\
\hline & & & \\
\hline & & & \\
\hline & & & \\
\hline & & & \\
\hline & & & \\
\hline
\end{tabular}


Idaho National Laboratory

\begin{tabular}{c|lll} 
HEAT TREATMENT DEVELOPMENT & Identifier: & PLN-5403 & \\
FOR THE TREAT LEU FUEL & Revision: & 0 & \\
ZR-ALLOY CLADDING VIA & Effective Date: & $07 / 02 / 2018$ & Page: iv of vi \\
TIME-TEMPERATURE DIAGRAMS & & &
\end{tabular}

INTENTIONALLY BLANK 


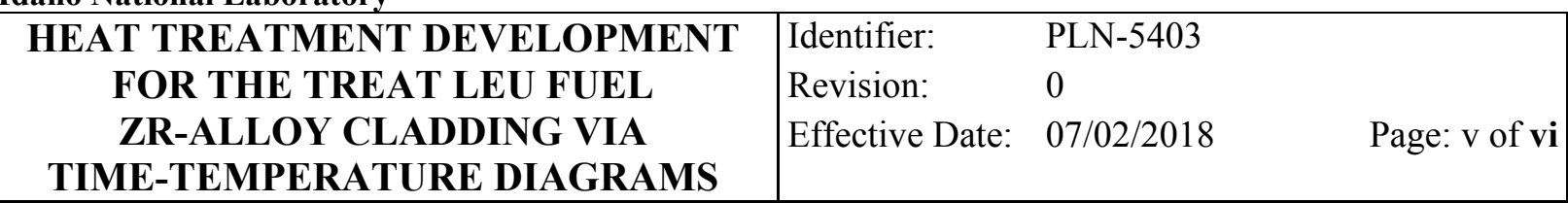

\section{CONTENTS}

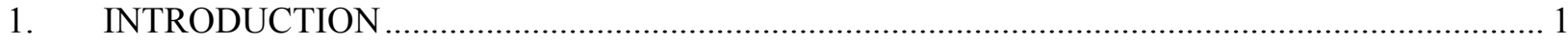

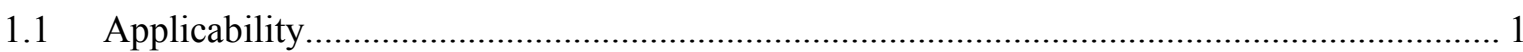

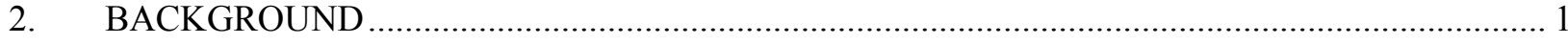

2.1 Original TREAT Fuel Assembly and Selection of LEU Fuel Assembly Clad ....................... 1

2.2 Technical Specification Limits on the Fuel Cladding [3] ................................................. 2

3. METALLURGY OF ZIRCONIUM AND ITS ALLOYS......................................................... 3

3.1 Thermomechanical Processes: Microstructural and Property Modifications........................... 3

3.1.1 Microstructure Recovery, Recrystallization and Grain Growth [5-6]........................ 3

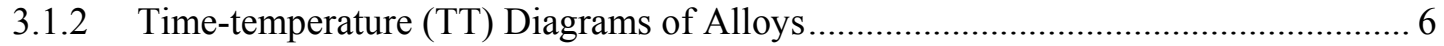

3.2 Physical Metallurgy of Zirconium and Zr-rich Alloys ................................................. 13

3.2.1 Cold Work and Recrystallization in Zirconium [8] ............................................. 13

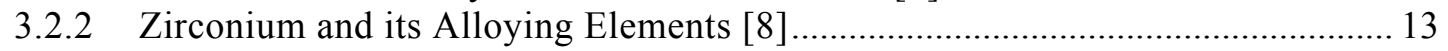

3.3 Literature Review: Zircaloy-4 Process-microstructure-properties..................................... 14

3.3.1 Time-transformation Diagrams for Zr-rich Alloys ................................................ 14

3.3.2 Cold Working Effect on Mechanical Properties of Zircaloy-4 ................................. 15

3.3.3 Thermomechanical Process and Thermal Treatment Effect on Zircaloy-4 Mechanical Properties .......................................................................................... 18

3.3.4 Heat Treatment Effect on Microstructure and Zircaloy-4 Corrosion........................ 25

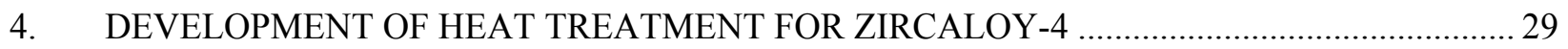

4.1 Time Temperature diagram development for Zircaloy-4 ................................................... 29

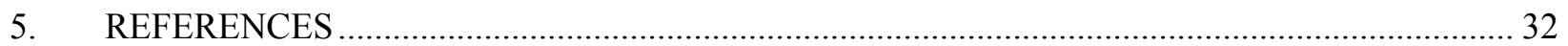

FIGURES

Figure 1. The influence of 1 hour annealing time and temperature on the tensile strength and ductility of a brass alloy. Grain size as a function of annealing temperature is indicated. Grain structures during recovery, recrystallization, and grain growth are shown schematically [5] 4

Figure 2. The variation of recrystallization temperature with percent cold work for iron [5]................... 5

Figure 3. The logarithm of grain diameter versus the logarithm of time for grain growth in brass

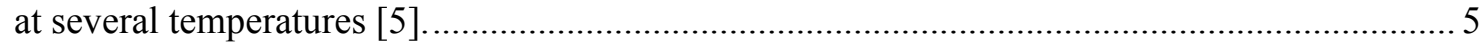

Figure 4. Iron-rich side of the Iron-Carbon binary phase diagram [adapted from 4]. .............................. 7

Figure 5. Fe-C eutectoid alloy partial TTT diagram, percent phase and microstructure evolution

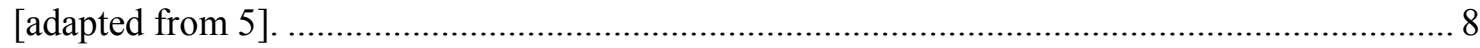

Figure 6. Percent austenite transformation into pearlite as a function of temperature [5] ........................ 9

Figure 7. Fe-C eutectoid alloy complete TTT diagram (left), with various cooling curves and resulting microstructure signature (right) [adapted from 5] ................................................. 9

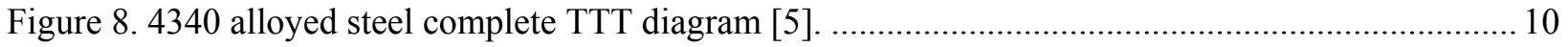




\begin{tabular}{|l|lll|} 
HEAT TREATMENT DEVELOPMENT & Identifier: & PLN-5403 \\
FOR THE TREAT LEU FUEL & Revision: & 0 & \\
ZR-ALLOY CLADDING VIA & Effective Date: & $07 / 02 / 2018$ & Page: vi of vi \\
TIME-TEMPERATURE DIAGRAMS & & & \\
\hline
\end{tabular}

Figure 9. Superimposition of the TTT and CCT diagrams for the Fe-C eutectoid alloy [5].

Figure 10. CCT diagram for eutectoid Fe-C alloy depicting the effect of cooling rate and transformation path on final microstructure [adapted from 5]

Figure 11. 4340 steel CCT diagram with various cooling curves and final microstructure....................... 12

Figure 12. TTT diagram for Zirconium 1.3wt\% Molybdenum alloy [10]........................................... 15

Figure 13. (a) Engineering stress-strain curves for annealed and cryo-rolled Zry-4 samples and

(b) variation of YS, UTS and \%EL with rolling reduction [14]. 16

Figure 14. (a) Comparison of calculated and experimental stress and (b) variation of strain hardening exponent with grain size from cryo-rolled Zr4 samples [14]. 17

Figure 15. Processing route, microstructure and grain texture for hydrided Zry-4 [15].

Figure 16. Influence on yield strength at $20^{\circ} \mathrm{C}$ due to different thermomechanical treatments, hydrogen content and sheet thickness [15].

Figure 17. Influence on ultimate tensile strength at $20^{\circ} \mathrm{C}$ due to different thermomechanical treatments, hydrogen content and sheet thickness [15].

Figure 18. Influence of thermomechanical treatments, hydrogen content and sheet thickness on ductility. (a) \% Elongation and (b) \% reduction of area at $20^{\circ} \mathrm{C} \mathrm{[15].}$

Figure 19. Influence on the ductility at $350^{\circ} \mathrm{C}$ due to different thermomechanical treatments, hydrogen content and sheet thickness [15].

Figure 20. As-received tube microstructure showing recrystallized $\alpha$-grains and round secondary phase precipitates at grain boundaries and within grains [16].

Figure $21 . \beta$-treated sample $\left(1000^{\circ} \mathrm{C}\right)$ showing typical microstructure with recrystallized elongated $\alpha$-grains non-uniform secondary phase precipitates at grain boundaries [16]

Figure 22. (a) Variation of $\alpha$-plate width and prior $\beta$-grain size and (b) ductility, yield and hoop strength as a function of heat treatment temperature [16]. .25

Figure 23. Microstructure - nodular corrosion relationship as a function of heat treatment [17]............26

Figure 24. Zry-4 Corrosion test: weight gain as a function of cooling rate from $\beta$-treatment [18] ...........28

Figure 25. Samples showing nodules after $500^{\circ} \mathrm{C}$ corrosion test for 24 and 48 hours for (a) as-received, (b) water-quenched, (c) air-cooled, and (d) furnace-cooled samples [18]...... .28

Figure 26. Preliminary simulations on the concentration of $\mathrm{Cr}$ during $\beta$-treatment for Zircaloy-4. 30

Figure 27. Preliminary computation of the TTT and CCT diagrams for Zircaloy-4 and various cooling paths.

\section{TABLES}

Table 1. Microstructure and microchemistry of Zircaloy-4 as a function of heat treatment [17]. 26

Table 2. Microstructure of Zircaloy-4 as a function of cooling rate from $\beta$-phase treatment temperature $\left(1,050^{\circ} \mathrm{C}\right.$ for 15 mins. $)$ [18]. 


\begin{tabular}{|c|lll|}
\hline HEAT TREATMENT DEVELOPMENT FOR & Identifier: & PLN-5403 \\
THE TREAT LEU FUEL & Revision: & 0 & \\
ZR-ALLOY CLADDING VIA & Effective Date: & $07 / 02 / 2018$ & Page: 1 of 33 \\
TIME-TEMPERATURE DIAGRAMS & & & \\
\hline
\end{tabular}

\section{INTRODUCTION}

The Idaho National Laboratory (INL) TREAT LEU Fuel Conversion Program is designing a new low-enriched uranium (LEU) fuel core for its Transient Reactor Test (TREAT) facility. The Fuel Engineering and Design team is in charge of the conceptualization, qualification and fabrication of the LEU fuel assembly. Due to the lack of commercial availability and sufficient processing information on the original cladding material, Zircaloy-3, a trade study has been performed and the down selection process is coming to completion in order to determine an adequate alloy for use as the TREAT LEU fuel assembly can. The assembly can (or cladding) material will be comprised of a Zr-alloy which will be fabricated into a columnar assembly to contain the composite fuel. A testing campaign has been undertaken to compare the properties of the legacy Zircaloy-3 material against other nuclear grade $\mathrm{Zr}$-alloys that are commercially available but were developed for use in water reactors.

As part of the cladding selection and specification process, there is a need to formulate an adequate thermomechanical process that will impart the optimum properties for the best performance under the expected TREAT reactor testing conditions and design basis accident (DBA) scenario. At the same time, this process must maintain functionality, hermeticity, and provide means to predict and understand any potential property degradation due to alloy microstructure aging over its 40 -years of expected service life.

\subsection{Applicability}

This review is intended to be used to understand the impact of the metallurgical state of a metal and alloy on the properties and in service behavior. The document was originally intended for Zircaloy-4 due to the state of the alloy testing when the document was elaborated. Also because there is more availability of technical information when compared to Zircaloy- 3 and $\mathrm{Zr}-1 \mathrm{Nb}$ alloys and more amenable for the purpose intended. Irrespective of the previous statement a plan for the development of an adequate heat treatment for the selected Zr-alloy clad for the TREAT LEU core is proposed through the use of Time-Temperature diagrams. Even though this document focuses mainly on Zircaloy-4 metallurgy, the analysis is applicable to the other Zr-alloys, and the proposed work plan shall be revised and updated to accommodate for the final selection of the Zr-alloy clad for the TREAT LEU core before any work is initiated.

\section{BACKGROUND}

\subsection{Original TREAT Fuel Assembly and Selection of LEU Fuel Assembly Clad}

The original TREAT reactor was designed primarily for operation in the transient, or pulsed, mode for destructive testing of prototypic fast reactor fuel pins. TREAT was designed conservatively to produce a pulse with a thermal neutron fluence of $3.5 \times 10^{3} \mathrm{n} / \mathrm{cm}^{2}$ averaged over the core. This design pulse produced a peak fuel temperature of $400^{\circ} \mathrm{C}$ for a core energy deposition of $1000 \mathrm{MJ}$. After extensive operating experience, the core temperature limit was raised to $600^{\circ} \mathrm{C}$, corresponding to $2100 \mathrm{MJ}$ in the reactor core. The limiting factor is the increasingly rapid oxidation rate of Zircaloy clad heated to high temperatures in air [1].

The design requirements and bases for the existing TREAT fuel assemblies derive from the original design of TREAT and are not to be modified or exceeded in the TREAT LEU reactor core. The Technical Specifications for TREAT require that the Limiting Safety System Settings be such that the maximum fuel temperature in TREAT does not exceed $600^{\circ} \mathrm{C}$ for normal operations. A safety limit of $820^{\circ} \mathrm{C}$ is specified for the fuel temperature. The basis for these limits involves the interplay between 


\begin{tabular}{|c|lll|}
\hline HEAT TREATMENT DEVELOPMENT FOR & Identifier: & PLN-5403 & \\
THE TREAT LEU FUEL & Revision: & 0 & \\
ZR-ALLOY CLADDING VIA & Effective Date: & $07 / 02 / 2018$ & Page: 2 of 33 \\
TIME-TEMPERATURE DIAGRAMS & & & \\
\hline
\end{tabular}

the oxidation rate of Zircaloy-3 in air at various temperatures, the assumption that the fuel and clad are at the same temperature, and the cooldown rate of the fuel. In setting $600^{\circ} \mathrm{C}$ and $820^{\circ} \mathrm{C}$ as the limiting requirement on the TREAT fuel assemblies for the Normal and Faulted operating design conditions, the effects of mechanical stability, graphite oxidation, graphite release of stored energy, outgassing and fission product diffusion, conversion of $\mathrm{UO}_{2}$ to $\mathrm{UC}$, Zircaloy-3 carburization, aluminum end fitting melting, and Zircaloy melting are all considered. The TREAT LEU Project requires that the TREAT fuel assembly clad not exceed $600^{\circ} \mathrm{C}$ for Normal conditions and $820^{\circ} \mathrm{C}$ for Faulted conditions. This limit will ensure clad integrity over the service life of the facility and will make loss of clad integrity unlikely under all credible conditions [2].

The Fuel Engineering and Design team is in charge of the conceptualization, qualification, and fabrication of the LEU fuel assembly. After a trade study and ongoing down selection process, most of the focus has been devoted to testing and comparison among the legacy Zircaloy-3 alloy properties and other promising materials, namely Zircaloy- 4 and $\mathrm{Zr}-1 \mathrm{Nb}$ alloys. Zry-4 and Zr-1Nb have adequate mechanical properties, a low thermal neutron cross-section, and, in particular, better oxidation resistance in air when compared to other commercially available nuclear alloys as ZIRLO and Zircaloy-2 alloys, which oxidize more readily in air environments [3] like the TREAT air-cooled reactor. The recent completion of the oxidation testing campaign has been critical to factor this important property into the final cladding alloy selection. The air oxidation testing was performed on prototypic tube samples (25-26 mils sheet formed into polygonal tubes with chamfered corners and longitudinal welds) to compare the oxidation resistance of Zry-3, Zry-4 and Zr-1 Nb alloys. The results show that the oxidation resistance of $\mathrm{Zr}-1 \mathrm{Nb}$ is comparable or superior to the Zircaloy-3 legacy alloy under TREAT reactor operation and accident conditions, respectively. Zircaloy-4 shows an ineffective long term oxidation resistance due to the lack of formation of a protective oxide caused by premature oxide breakaway when compared to Zry3 and $\mathrm{Zr}-1 \mathrm{Nb}$, this is evident at temperatures above $500^{\circ} \mathrm{C}[3-4]$.

\subsection{Technical Specification Limits on the Fuel Cladding [5]}

The melting point of zirconium is $1843^{\circ} \mathrm{C}$; the melting points of the various Zircaloys are near this value. The temperature safety limit that is placed on the TREAT fuel cladding is $820^{\circ} \mathrm{C}$. The lower limit is used because of the oxidation and development of brittleness that can occur when high temperature Zircaloy contacts air.

It is useful to consider the limits that are used in licensing Light Water Reactors (LWRs). The Nuclear Regulatory Commission (NRC) has established limits on the operation of nuclear reactors with Zircaloy-clad fuel. These NRC limits are associated with the loss-of-coolant accident (LOCA) which is the design basis accident in a LWR. Although the reaction in LWRs is between Zircaloy and steam, there is some relevance to the Zircaloy air reaction in TREAT. The NRC limits that are of interest in establishing limits for TREAT are:

1. Peak Cladding Temperature - The calculated maximum fuel element cladding temperature shall not exceed $1205^{\circ} \mathrm{C}$. This is based upon the reaction rate of Zircaloy in steam. There is an $820^{\circ} \mathrm{C}$ limit in TREAT, justified by reaction rates of Zircaloy in air.

2. Maximum Cladding oxidation - The total calculated oxidation of the fuel element cladding shall not exceed 0.17 times the total cladding thickness before oxidation. The TREAT FSAR value differs from the NRC value for LWRs because it specifies that 15-mils of the original clad thickness is the limit of oxidation for a 25 -mils thick cladding. The intent of this requirement and still applicable to air is to guard against: 1) runaway oxidation of the cladding due to the exponential character of the reaction rate, and 2) the onset of brittleness (nil ductility) in the rest of the clad that is due to oxygen incursion into the grain boundaries as a result of the Zircaloy steam reaction. The increase in oxygen 


\begin{tabular}{|c|c|c|c|}
\hline $\begin{array}{c}\text { HEAT TREATMENT DEVELOPMENT FOR } \\
\text { THE TREAT LEU FUEL } \\
\text { ZR-ALLOY CLADDING VIA } \\
\text { TIME-TEMPERATURE DIAGRAMS }\end{array}$ & $\begin{array}{l}\text { Identifier: } \\
\text { Revision: } \\
\text { Effective Date: }\end{array}$ & $\begin{array}{l}\text { PLN-5403 } \\
0 \\
07 / 02 / 2018\end{array}$ & Page: 3 of $\mathbf{3 3}$ \\
\hline
\end{tabular}

dissolved in $\mathrm{Zr}$ and its alloys causes an increase in the overall hardness and loss of ductility of the saturated matrix. Hence, brittleness also occurs in Zircaloy exposed to air at high temperature and can be further exacerbated due to the Nitrogen ingress and nitriding of the alloy. In addition, the selection of $820^{\circ} \mathrm{C}$ as the limit for the Zircaloy clad heating in TREAT has been chosen to stay below the alpha-to-beta phase transition temperature that would produce significant changes in the material properties of the assembly, e.g., large oxygen pickups in the high temperature body-centered cubic (BCC) phase.

3. Coolable Geometry - Calculated changes in core geometry shall be such that the core remains amenable to cooling. This requirement is directly applicable to the TREAT fuel elements.

4. Long-term Cooling - After an accident, the calculated core temperature shall be maintained at an acceptably low value, and decay heat shall be removed for the extended period of time required by the long-lived radioactivity remaining in the core. This requirement is applicable to TREAT and is satisfied by the blower(s) being operational and/or heat loss to the surroundings. There is stored energy that must be removed from the fuel but no decay heat.

\section{METALLURGY OF METALS AND ALLOYS}

\subsection{Thermomechanical Processes: Microstructural and Property Modifications}

The process-structure-property relationship is the paradigm of the metals and materials science and engineering field. It is the heart of every engineered material because the functionality and behavior of a material will largely depend on the careful selection of the material system and the optimization of the processing steps to produce the most adequate properties for the material to perform at its best under the specific service conditions and to avoid catastrophic failure. A thermomechanical process on a metal or alloy consists of, first, forming the material into the desired shape through hot and/or cold working processes. The second step is application of a final heat treatment (i.e., process anneal, stress-relief anneal, recrystallization, precipitation hardening, aging, normalization, or tempering thermal treatments) to produce the desired microstructure that will convey particular properties to the alloy.

\subsubsection{Microstructure Recovery, Recrystallization and Grain Growth [6-7]}

In engineering processing terms, severe plastic cold working is typically carried out for changing the shape of a metallic work piece. In physical metallurgy terms, cold deformation leads to the increase of the internal stored energy. This increase in the stored energy in microstructurally associated with the accumulation of lattice defects. Plastically deforming a polycrystalline metal specimen at temperatures that are low relative to its absolute melting temperature produces microstructural and property changes that include a change in grain shape, strain hardening, and an increase in dislocation density. These high-lattice defect densities lead to changes in a number of properties, such as the electrical resistivity, hardness, strength, toughness, and ductility with the amount of cold working. In addition, the corrosion behavior is altered since the potential changes around dislocations render deformed zones preferred attacking points to oxidation phenomena. These properties and structures may completely or partially revert back to the pre cold-worked states by appropriate heat treatment to render cold-worked metallic materials back into a softer and, hence, easily formable state. Such restoration results from different processes that occur at elevated temperatures: recovery, recrystallization, and grain growth or competitive grain coarsening.

Recovery-Physical properties such as electrical and thermal conductivities are recovered to their precold-worked states. 


\begin{tabular}{|c|c|c|c|}
\hline $\begin{array}{c}\text { HEAT TREATMENT DEVELOPMENT FOR } \\
\text { THE TREAT LEU FUEL } \\
\text { ZR-ALLOY CLADDING VIA } \\
\text { TIME-TEMPERATURE DIAGRAMS }\end{array}$ & $\begin{array}{l}\text { Identifier: } \\
\text { Revision: } \\
\text { Effective Date: }\end{array}$ & $\begin{array}{l}\text { PLN-5403 } \\
0 \\
07 / 02 / 2018\end{array}$ & Page: 4 of 33 \\
\hline
\end{tabular}

Recrystallization -the mechanical properties that were changed as a result of cold working are restored to their precold-worked values, i.e., the metal becomes more ductile. Recrystallization process depends on time, temperature, the amount of prior cold work, and the purity of the alloy. The recrystallization temperature is the temperature at which recrystallization just reaches completion in $1 \mathrm{~h}$. In practical terms, this usually means holding the cold deformed materials at a temperature above about $1 / 3$ to $1 / 2$ of their respective absolute melting point $\left(T_{m}\right)$ for 1 hour. As an example the influence of temperature on mechanical properties for a brass alloy as a function of the temperature a $1 \mathrm{hr}$ isothermal treatent is demonstrated in Figure 1,. There exists some critical degree of cold work below which recrystallization cannot be made to occur, as shown in Figure 2; normally, this is between 2\% and 20\% cold work. For pure metals, the recrystallization temperature is normally $0.4 \mathrm{~T}_{\mathrm{m}}$, and, for some commercial alloys, it may run as high as $0.7 \mathrm{~T}_{\mathrm{m}}$.

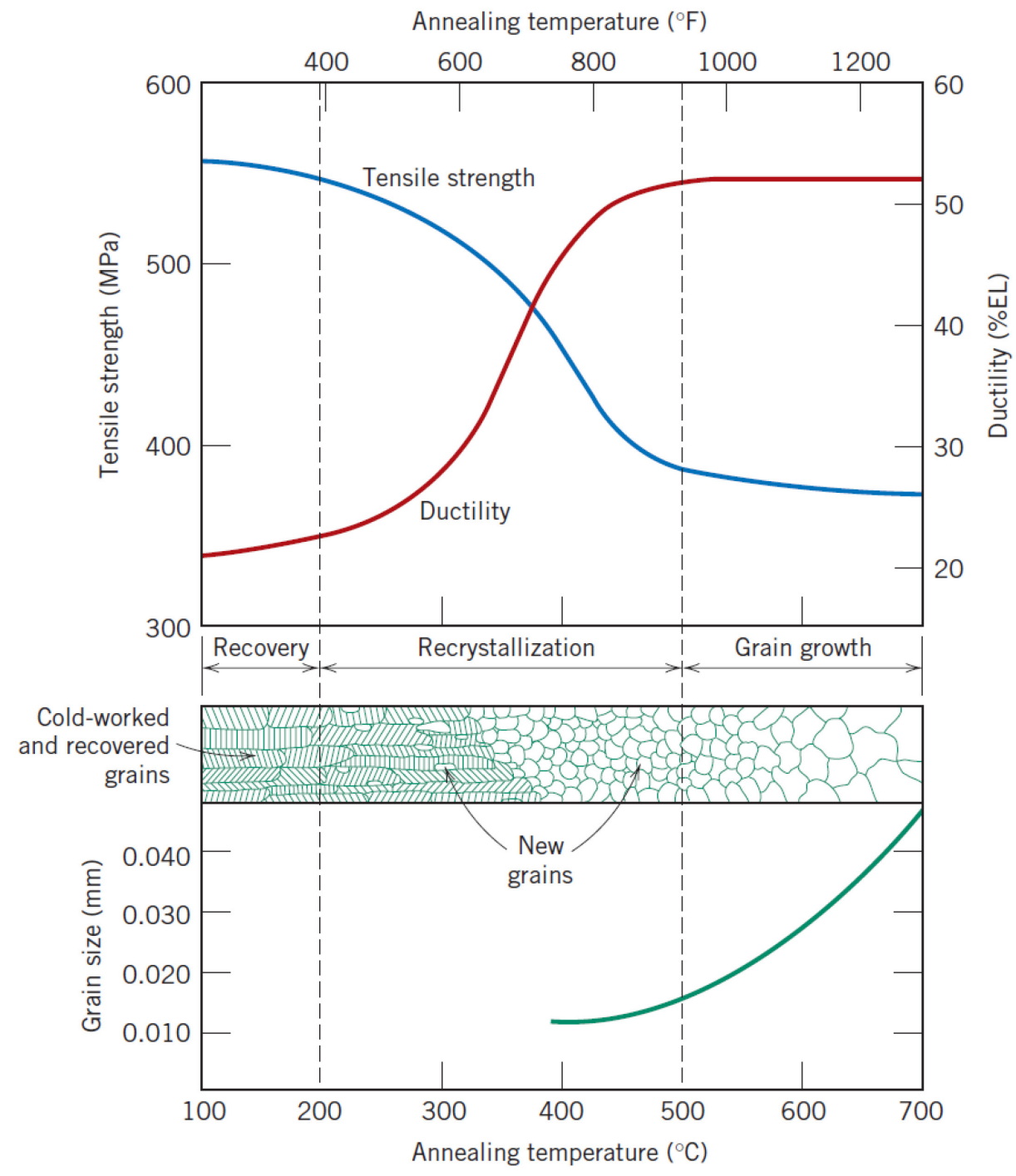

Figure 1. The influence of 1-hour annealing and temperature on the tensile strength and ductility of a brass alloy [6]. 
Identifier: Revision:

PLN-5403

Effective Date: $07 / 02 / 2018$

Page: 5 of $\mathbf{3 3}$

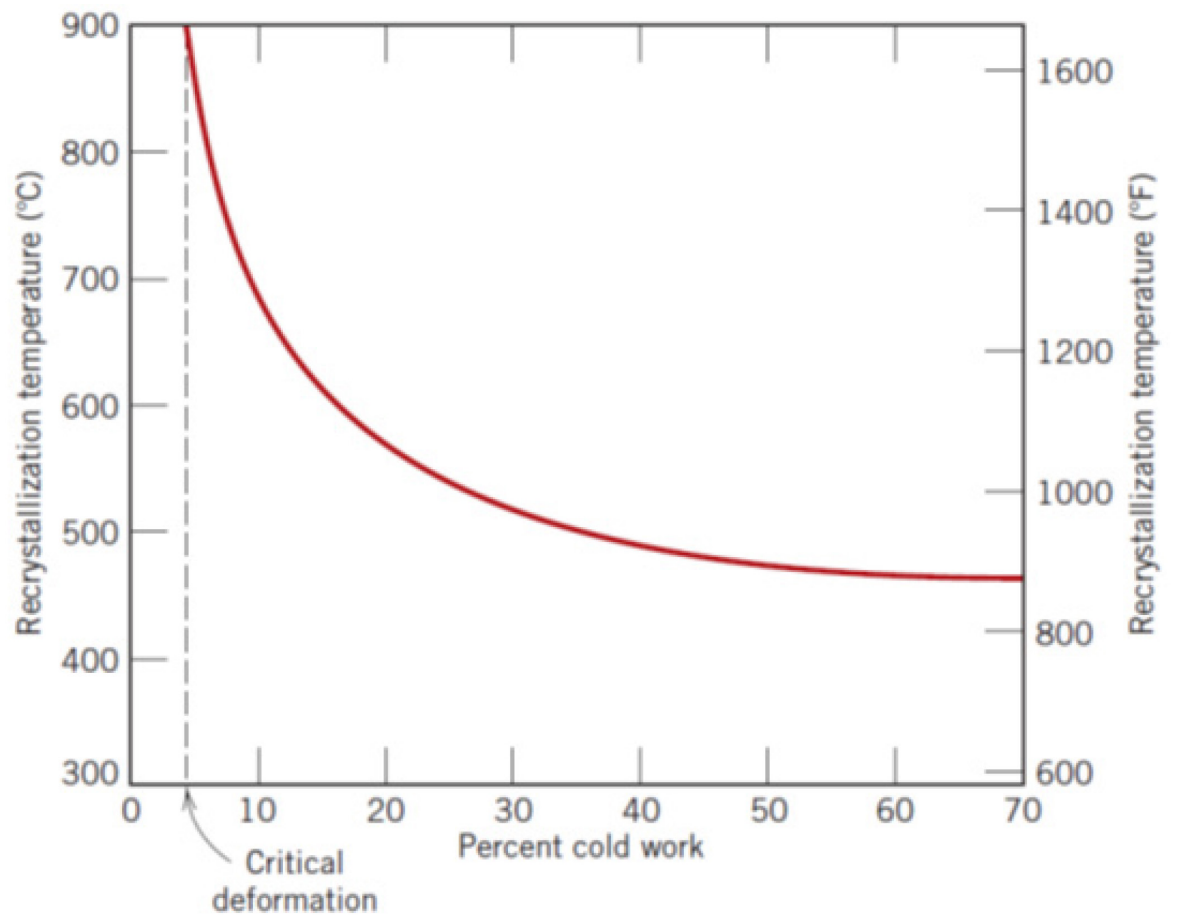

Figure 2. The variation of recrystallization temperature with percent cold work for iron [6].

Grain growth - The mechanical properties at room temperature of a fine-grained metal are usually superior (i.e., higher strength and toughness) to those of coarse-grained ones. If the grain structure of a single-phase alloy is coarser than that desired, refinement may be accomplished by plastically deforming the material, then subjecting it to a recrystallization heat treatment, as described previously.The dependence of grain size on time and temperature is demonstrated in Figure 3 for a brass alloy at several temperatures. At lower temperatures, the curves are linear, but grain growth proceeds more rapidly as temperature increases, and the curves are displaced upward to larger grain sizes. This is due to the enhancement of diffusion rate with increased temperature.

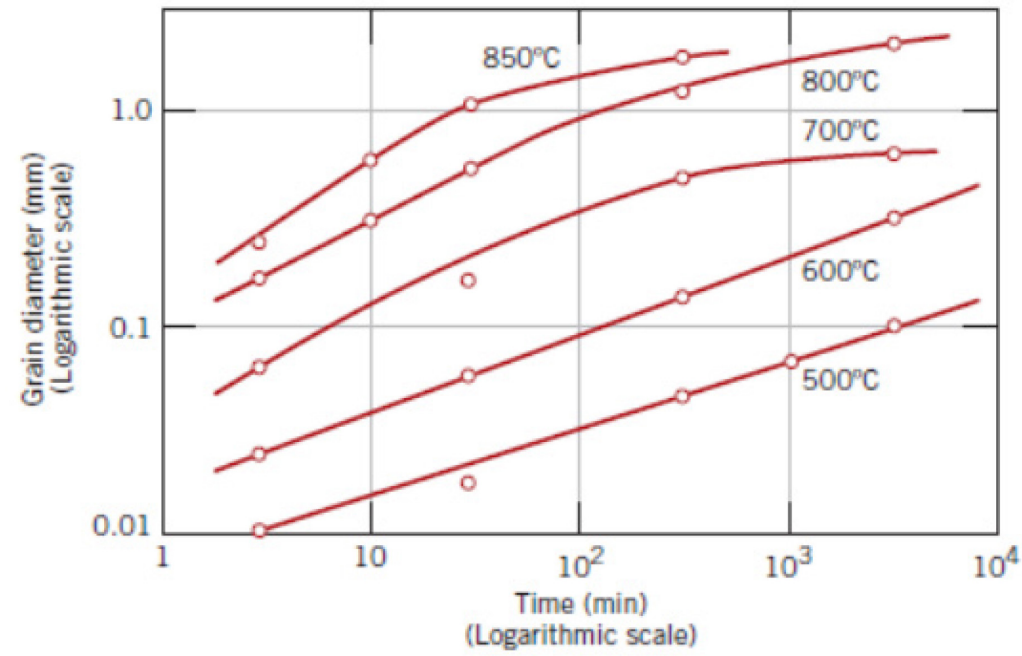

Figure 3. Grain diameter as a function of time for various isothermal thermal treatments [6]. 


\begin{tabular}{|c|c|c|c|}
\hline $\begin{array}{c}\text { HEAT TREATMENT DEVELOPMENT FOR } \\
\text { THE TREAT LEU FUEL } \\
\text { ZR-ALLOY CLADDING VIA } \\
\text { TIME-TEMPERATURE DIAGRAMS }\end{array}$ & $\begin{array}{l}\text { Identifier: } \\
\text { Revision: } \\
\text { Effective Date: }\end{array}$ & $\begin{array}{l}\text { PLN-5403 } \\
0 \\
07 / 02 / 2018\end{array}$ & Page: 6 of $\mathbf{3 3}$ \\
\hline
\end{tabular}

\subsubsection{Time-temperature (TT) Diagrams of Alloys}

Solid-state phase transformations occur when one or more of the phases in a system change their state of aggregation, crystal structure, and degree of order or composition resulting from a reconfiguration of the constituent particles comprising the phase. The phase changes are stimulated by modifications in temperature, pressure, concentration, mechanical distortion, and other parameters that impact the thermodynamic potential of the system. The thermodynamic driving force for the phase reconfiguration into a more stable condition is a decrease in the Gibbs free energy of the system towards the attainment of a new equilibrium state.

Metals are rarely used in their pure form, since they are usually alloyed with other elements to produce improved or new properties that could not be possible otherwise. Transformation diagrams are of enormous value to understand non-equilibrium phase transformations, and are instrumental for the prediction of the relationships among heat treatment, the development of microstructure, and mechanical properties of an alloy. There are two types of temperature transformation diagrams, those developed under isothermal conditions termed isothermal transformation (IT) (also referred to as time-temperature transformation [TTT]) diagrams and the ones plotted for continuous cooling conditions known as continuous cooling transformation (CCT) diagrams [8].

In order to exemplify the use of TTT diagrams we will look at the Fe-C system. If we consider a plain carbon steel alloy consisting of $\mathrm{Fe}-0.76 \mathrm{wt} \% \mathrm{C}$, this corresponds to the eutectoid composition in the $\mathrm{Fe}-\mathrm{C}$ diagram shown with a black bold arrow in Figure 4. If this alloy is heated above the eutectoid temperature $727^{\circ} \mathrm{C}$ and normalized in the austenite region $(\gamma-\mathrm{Fe})$, and if it is subsequently rapidly cooled down to $675^{\circ} \mathrm{C}$ and held at that temperature (A-B-C line), the austenite phase will not be stable anymore. The alloy then will go through the eutectoid reaction $\gamma \rightarrow \alpha+\mathrm{Fe}_{3} \mathrm{C}$, which is fundamental to the development of microstructures in steels. However, the reaction will not be immediate, and the transformation of austenite into ferrite $(\alpha \mathrm{Fe})$ and cementite $\left(\mathrm{Fe}_{3} \mathrm{C}\right)$, also known as Pearlite $\left(\alpha+\mathrm{Fe}_{3} \mathrm{C}\right)$, will be temperature-time dependent. Figure 5 shows the upper section, or upper half of the "nose," of the TTT diagram for this specific Fe-C eutectoid alloy. It can be observed that the reaction will commence at point $\mathrm{C}$ (red line identifying eutectoid reaction beginning), about $50 \%$ of the austenite will have transformed into pearlite after about one minute, and the reaction will have come to completion in approximately 10 minutes at point $\mathrm{D}$ (blue line signaling eutectoid reaction end or completion). The bottom graph shows a schematic of the microstructure transformation at $625^{\circ} \mathrm{C}$, which is analogous to the transformation at $727^{\circ} \mathrm{C}$. However, the transformation rate will be affected by the annealing temperature, and the alloy will undergo a reaction that will be governed by the shape of the TTT "nose." Figure 5 shows how the transformation rate is affected by the annealing temperature. 


\begin{tabular}{|c|c|c|c|}
\hline $\begin{array}{c}\text { HEAT TREATMENT DEVELOPMENT FOR } \\
\text { THE TREAT LEU FUEL } \\
\text { ZR-ALLOY CLADDING VIA } \\
\text { TIME-TEMPERATURE DIAGRAMS }\end{array}$ & $\begin{array}{l}\text { Identifier: } \\
\text { Revision: } \\
\text { Effective Date: }\end{array}$ & $\begin{array}{l}\text { PLN-5403 } \\
0 \\
07 / 02 / 2018\end{array}$ & Page: 7 of $\mathbf{3 3}$ \\
\hline
\end{tabular}

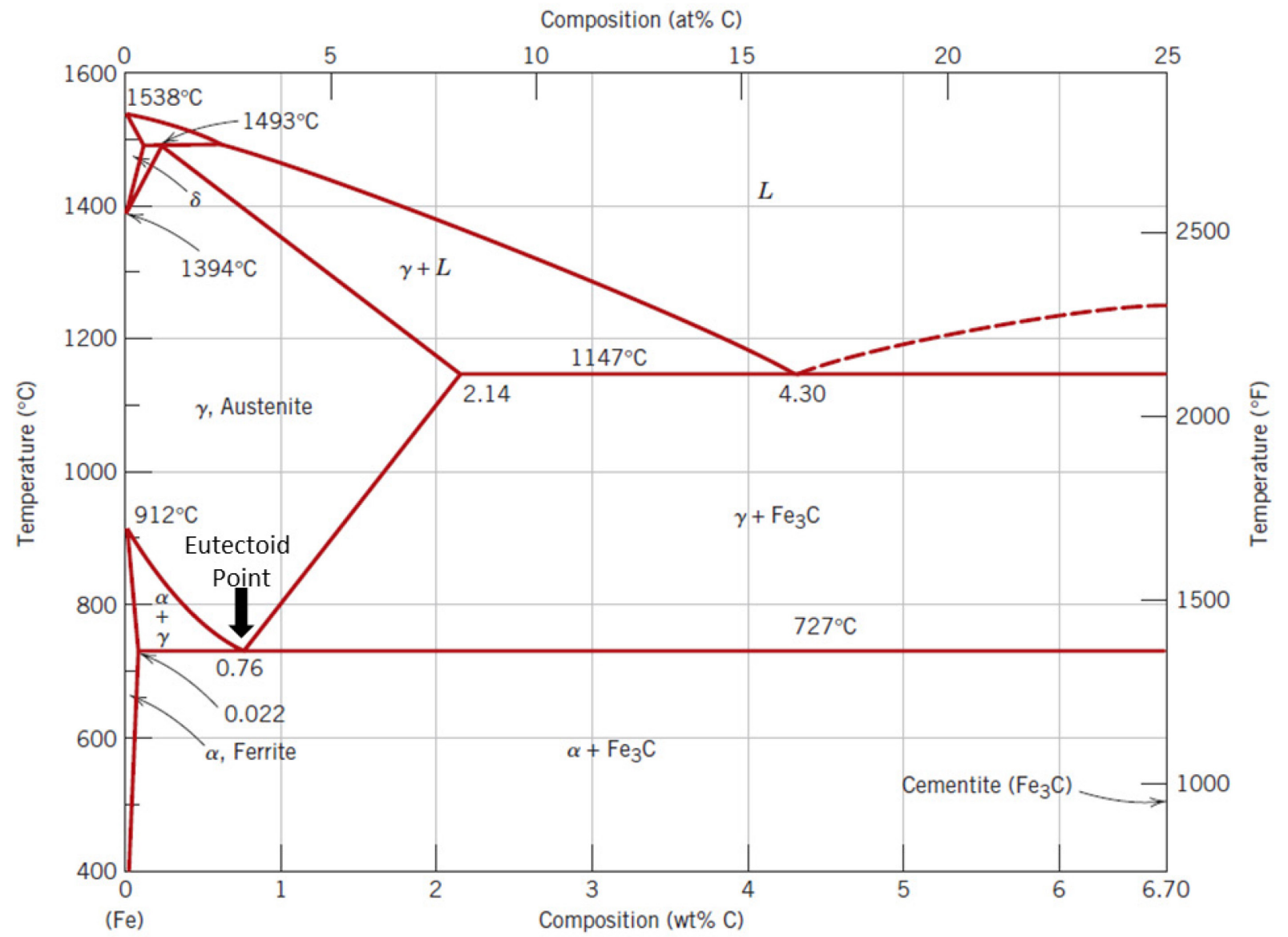

Figure 4. Iron-rich side of the Iron-Carbon binary phase diagram [adapted from 5]. 
HEAT TREATMENT DEVELOPMENT FOR

THE TREAT LEU FUEL

ZR-ALLOY CLADDING VIA

TIME-TEMPERATURE DIAGRAMS
Identifier:

Revision:

Effective Date: 07/02/2018
PLN-5403

0
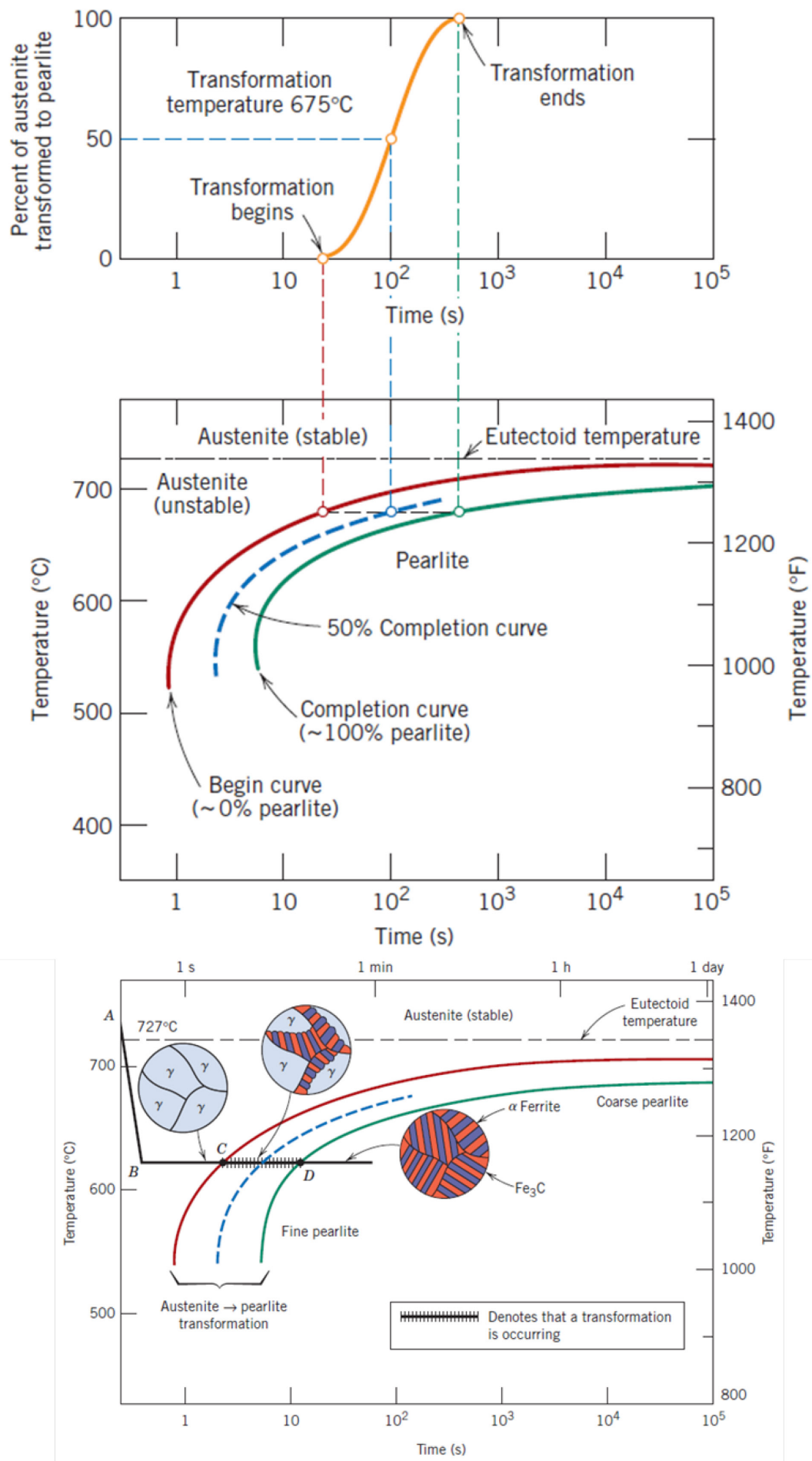

Figure 5. Fe-C eutectoid alloy partial TTT diagram, percent phase and microstructure evolution [adapted from 5]. 


\begin{tabular}{|c|lll|}
\hline $\begin{array}{c}\text { HEAT TREATMENT DEVELOPMENT FOR } \\
\text { THE TREAT LEU FUEL }\end{array}$ & Identifier: & PLN-5403 & \\
ZR-ALLOY CLADDING VIA & Revision: & 0 & \\
TIME-TEMPERATURE DIAGRAMS & Effective Date: & $07 / 02 / 2018$ & Page: 9 of $\mathbf{3 3}$ \\
\hline
\end{tabular}

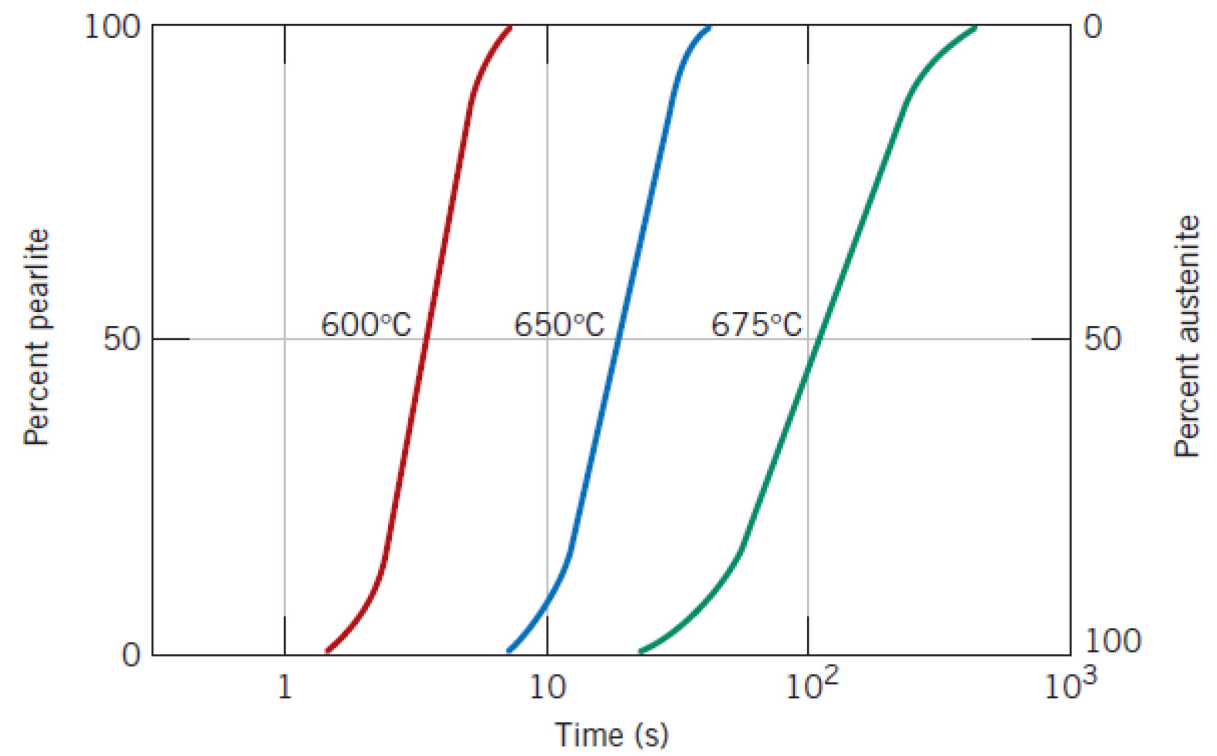

Figure 6. Percent austenite transformation into pearlite as a function of temperature [6].
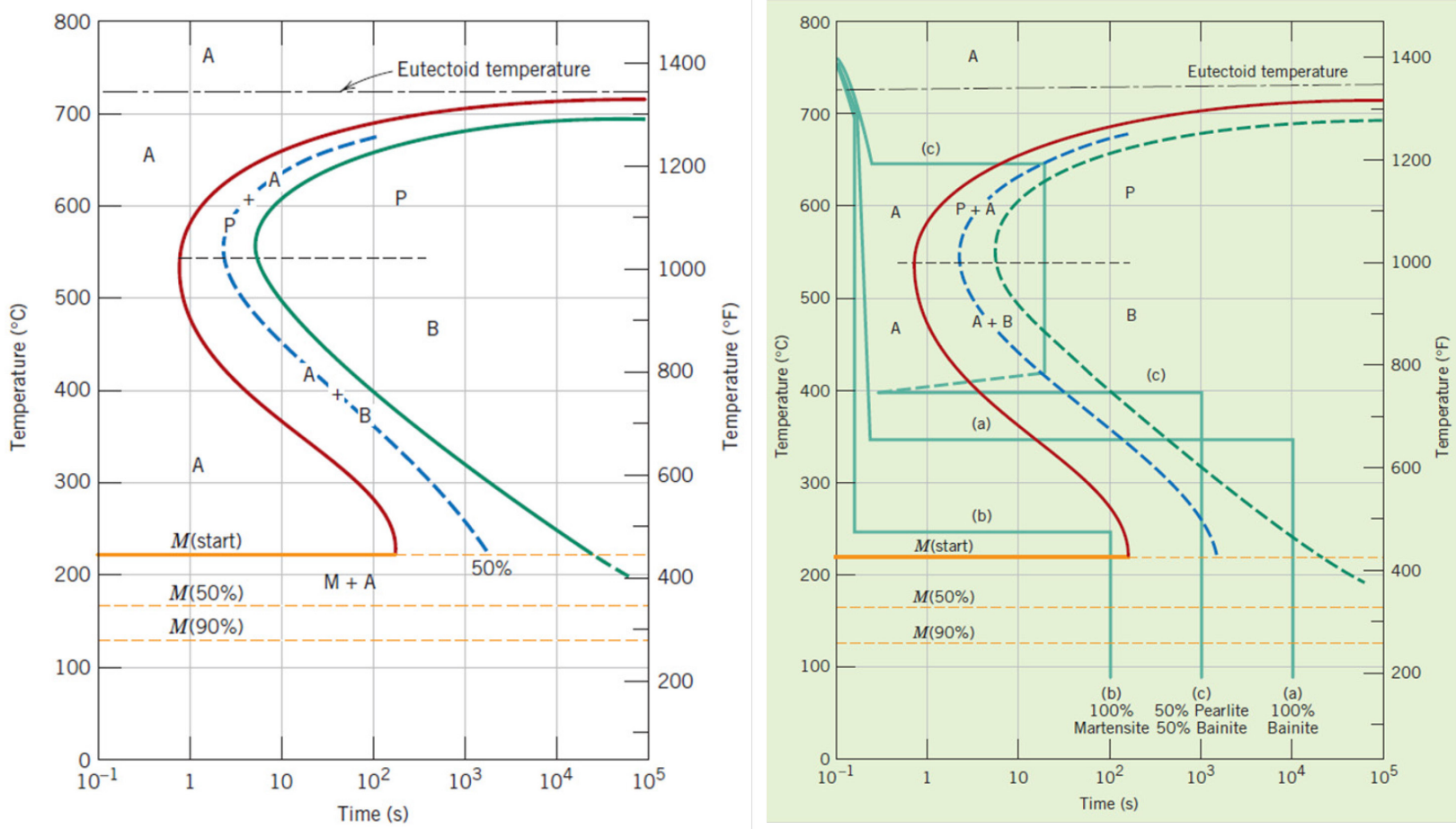

Figure 7. Fe-C eutectoid alloy complete TTT diagram (left), with various cooling curves and resulting microstructure signature (right) [adapted from 5].

Figure 7 (left) shows the complete TTT diagram for the eutectoid Fe-C alloy along with different regions for the formation of metastable phases like martensite, and distinct versions of the $\alpha+\mathrm{Fe}_{3} \mathrm{C}$ eutectoid phase known as Bainite, which possess different mechanical properties than pearlite. Also, Figure 7 (right) shows a variety of possible cooling paths (green lines) and the resulting microstructural 


\begin{tabular}{|c|c|c|c|}
\hline $\begin{array}{c}\text { HEAT TREATMENT DEVELOPMENT FOR } \\
\text { THE TREAT LEU FUEL } \\
\text { ZR-ALLOY CLADDING VIA } \\
\text { TIME-TEMPERATURE DIAGRAMS }\end{array}$ & $\begin{array}{l}\text { Identifier: } \\
\text { Revision: } \\
\text { Effective Date: }\end{array}$ & $\begin{array}{l}\text { PLN-5403 } \\
0 \\
07 / 02 / 2018\end{array}$ & Page: 10 of $\mathbf{3 3}$ \\
\hline
\end{tabular}

features. Furthermore, in order to shed some insight on the effect of adding multiple alloying elements to iron and its impact on the TTT diagram, Figure 8 shows the TTT diagram of 4340 Steel which contains about $95-96 \mathrm{wt} \% \mathrm{Fe}$ but has been alloyed with specific concentrations of $\mathrm{C}, \mathrm{Cr}, \mathrm{Mn}, \mathrm{Mo}, \mathrm{Ni}, \mathrm{P}, \mathrm{Si}$ and $\mathrm{S}$. The previous discussion gives us an idea of the complexity and usefulness of TTT diagrams.

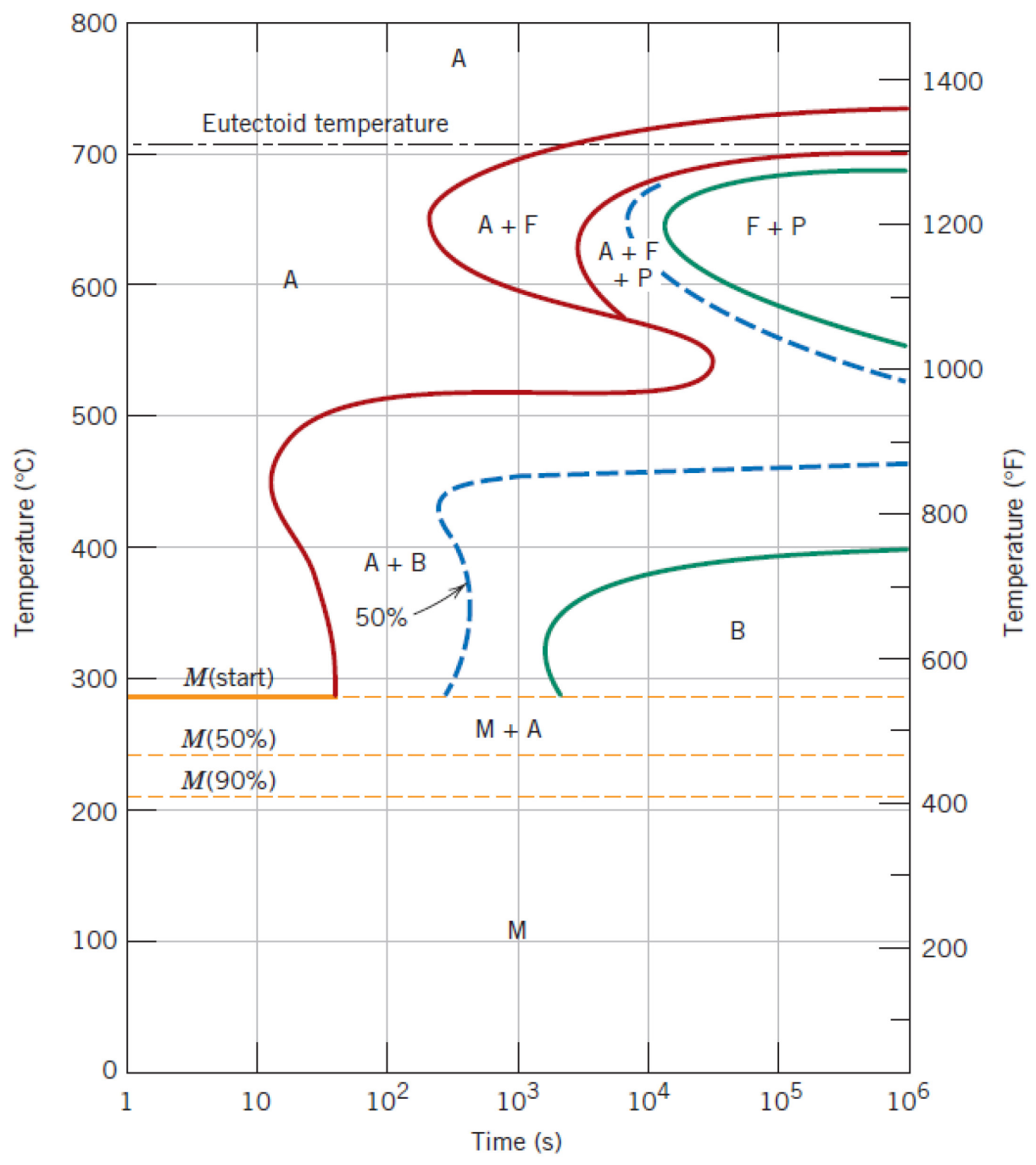

Figure 8. 4340 alloyed steel complete TTT diagram [6].

Isothermal heat treatments are not the most practical to conduct because an alloy must be rapidly cooled to and maintained at an elevated temperature from a higher temperature above the eutectoid. Most heat treatments for steels and commercial alloys involve the continuous cooling of the material to room temperature. An isothermal transformation diagram is valid only for conditions of constant temperature. For continuous cooling, the time required for a reaction to begin and end is delayed. Therefore, this diagram must be modified for transformations that occur as the temperature is constantly changing. In CCT diagrams, the TTT curves are shifted to longer times and lower temperatures, as indicated in Figure 9 for an iron-carbon alloy of eutectoid composition. 


\begin{tabular}{|c|lll|}
\hline HEAT TREATMENT DEVELOPMENT FOR & Identifier: & PLN-5403 & \\
THE TREAT LEU FUEL & Revision: & 0 & \\
ZR-ALLOY CLADDING VIA & Effective Date: & $07 / 02 / 2018$ & Page: 11 of 33 \\
TIME-TEMPERATURE DIAGRAMS & & & \\
\hline
\end{tabular}

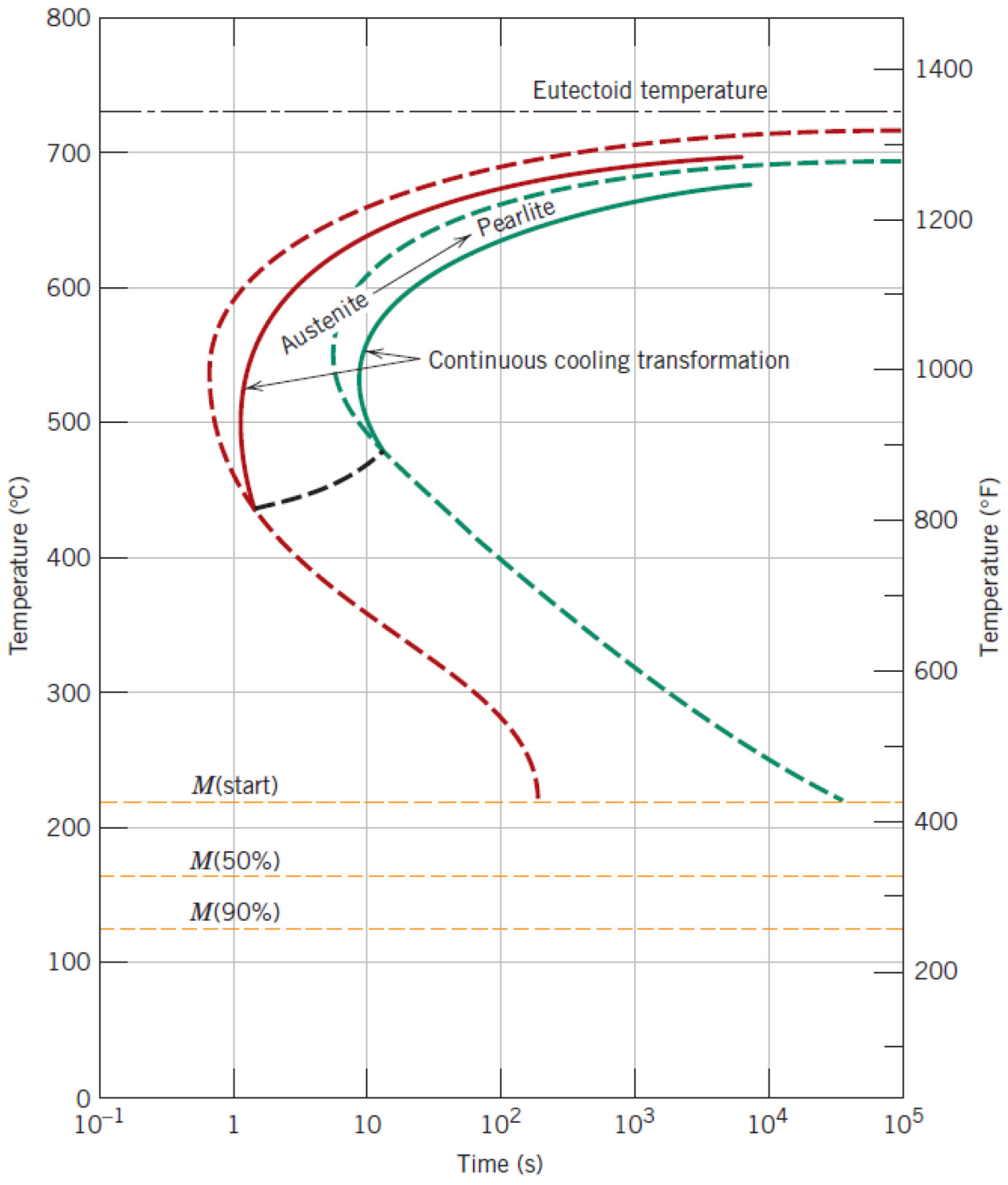

Figure 9. Superimposition of the TTT and CCT diagrams for the Fe-C eutectoid alloy [6].

Finally, Figure 10 and Figure 11 show the impact of cooling rate and transformation path on the final microstructure of a eutectoid iron-carbon alloy and 4340 alloyed steel, respectively. 
HEAT TREATMENT DEVELOPMENT FOR

THE TREAT LEU FUEL

ZR-ALLOY CLADDING VIA TIME-TEMPERATURE DIAGRAMS

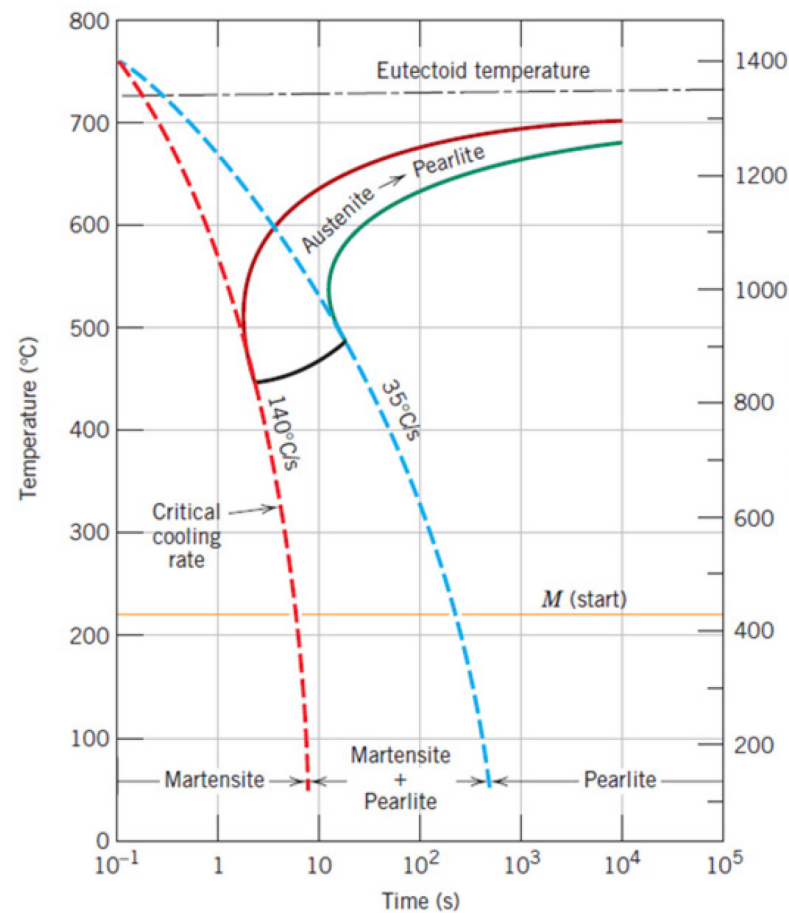

Identifier:

Revision:

Effective Date: 07/02/2018

PLN-5403

0

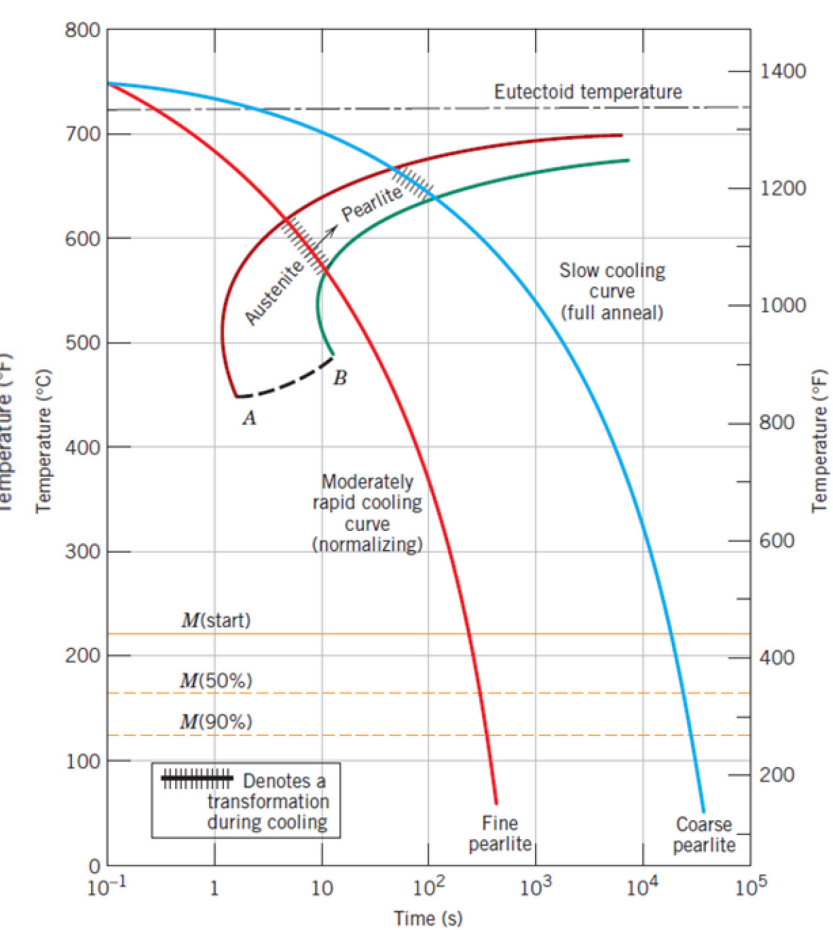

Figure 10. CCT diagram for eutectoid Fe-C alloy depicting the effect of cooling rate and transformation path on final microstructure [adapted from 5].

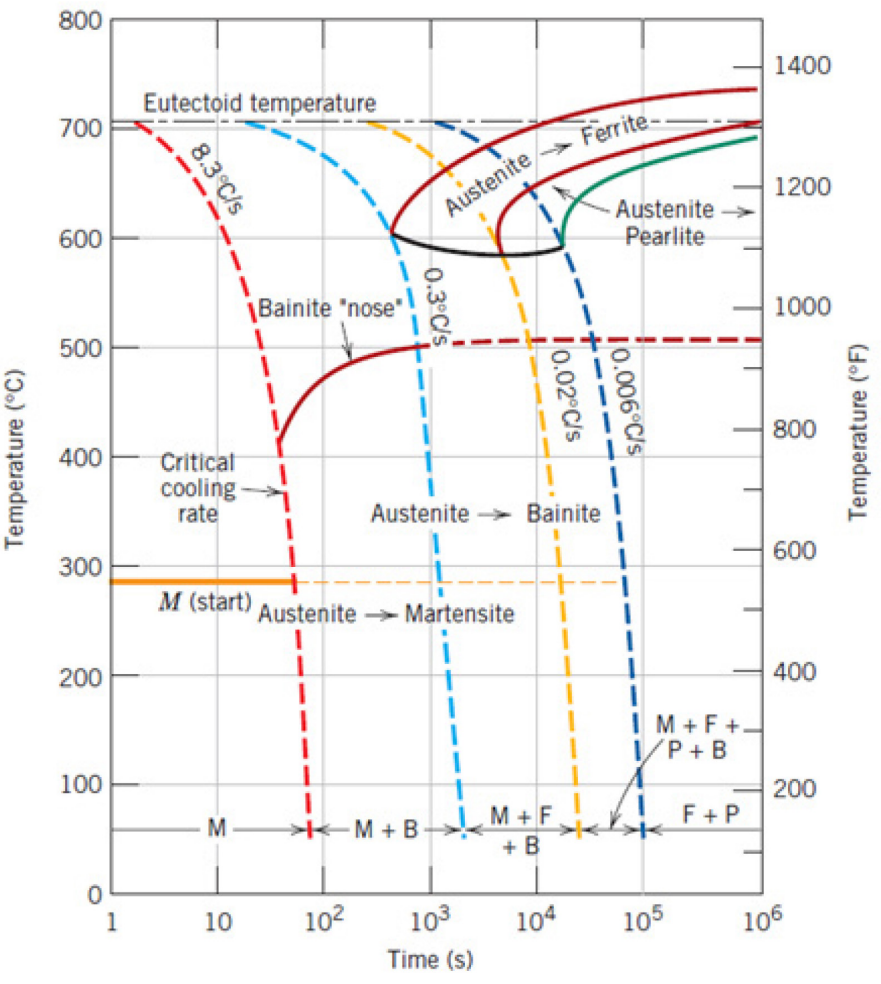

Figure 11. 4340 steel CCT diagram with various cooling curves and final microstructure. 


\begin{tabular}{|c|lll|}
\hline HEAT TREATMENT DEVELOPMENT FOR & Identifier: & PLN-5403 & \\
THE TREAT LEU FUEL & Revision: & 0 & \\
ZR-ALLOY CLADDING VIA & Effective Date: & $07 / 02 / 2018$ & Page: 13 of $\mathbf{3 3}$ \\
TIME-TEMPERATURE DIAGRAMS & & & \\
\hline
\end{tabular}

Isothermal and continuous cooling transformation diagrams are, in a sense, phase diagrams in which the parameter of time is introduced. Each is experimentally determined for an alloy of specified composition, with the variables being temperature and time. The TTT and CCT diagrams are essential in an alloy's processing because they allow prediction of the final microstructure, hence properties, for a constant temperature and continuous cooling heat treatments, respectively.

\subsection{Physical Metallurgy of Zirconium and Zr-rich Alloys}

\subsubsection{Cold Work and Recrystallization in Zirconium [9]}

The degree to which unalloyed zirconium can be cold worked depends both on metal purity and on the method of reduction. Zirconium work hardens rapidly, reaching maximum hardness and strength after cold reduction of only about $20 \%$. However, reductions of about $50 \%$ are common during cold rolling, and reductions of $80 \%$ can be accomplished in some instances using special bidirectional rolling machines. Initially, deformation results in twinning, which reorients the lattice for slip; slip is the primary mechanism for cold working. In heavily cold-worked zirconium, recrystallization commences at about $510^{\circ} \mathrm{C}\left(950^{\circ} \mathrm{F}\right)$. Process annealing of such material is usually conducted at 620 to $790^{\circ} \mathrm{C}\left(1150\right.$ to $\left.1450^{\circ} \mathrm{F}\right)$. Recrystallization will occur in times as short as $15 \mathrm{~min}$, but much longer times are normally used to ensure that the entire furnace load reaches temperature. Grain growth is nearly nonexistent at the usual annealing temperatures, and 100 hours or more are required to produce grain growth of 2 to 3 American Society for Testing and Materials (ASTM) sizes.

\subsubsection{Zirconium and its Alloying Elements [9]}

Oxygen - considered a controlled solid-solution alloying agent. Oxygen was originally considered a troublesome impurity in zirconium, and substantial effort was devoted to its elimination. However, when oxygen levels were finally reduced below $1000 \mathrm{ppm}$, it was found that required strength levels in Zircaloy could no longer be met. Oxygen is a potent strengthener at room temperature, but much of its effectiveness is lost at elevated temperatures.

Alpha-stabilizing elements - These constituents raise the temperature of the allotropic $\alpha$-to- $\beta$ transformation. These elements include aluminum, antimony, tin, beryllium, lead, hafnium, nitrogen, oxygen, and cadmium. Phase diagrams for many of the binary alloy systems formed between these various elements and zirconium exhibit a peritectic or a peritectoid reaction at the zirconium-rich end.

Beta-stabilizing elements - These constituents lower the $\alpha$-to- $\beta$ transformation temperature. Typical $\beta$ stabilizers include iron, chromium, nickel, molybdenum, copper, niobium, tantalum, vanadium, thorium, uranium, tungsten, titanium, manganese, cobalt, and silver. Zirconium-rich alloys with beta stabilizing elements typically include a eutectoid reaction and often a eutectic reaction as well at the zirconium-rich end of the phase diagram.

Low-solubility intermetallic compound formers - such as carbon, silicon, and phosphorus have very low solubility in zirconium, even at temperatures in excess of $1000^{\circ} \mathrm{C}\left(1830^{\circ} \mathrm{F}\right)$. They readily form stable intermetallic compounds that are relatively insensitive to heat treatment.

Impurities such as iron and chromium are soluble in $\beta \mathrm{Zr}$ but relatively insoluble in $\alpha \mathrm{Zr}$, where they exist primarily as intermetallic compounds. The size and distribution of these secondary phases are largely governed by reactions that take place during the last transformation from $\beta$ to $\alpha$ and by subsequent mechanical working at lower temperatures. Heating at temperatures near the $\alpha-\beta$ transition, or in the $\alpha+\beta$ region, causes migration of many impurities to grain boundaries. This 
Idaho National Laboratory

\begin{tabular}{|c|lll|}
\hline $\begin{array}{c}\text { HEAT TREATMENT DEVELOPMENT FOR } \\
\text { THE TREAT LEU FUEL }\end{array}$ & Identifier: & PLN-5403 & \\
ZR-ALLOY CLADDING VIA & Revision: & 0 & \\
TIME-TEMPERATURE DIAGRAMS & Effective Date: & $07 / 02 / 2018$ & Page: 14 of $\mathbf{3 3}$ \\
\hline
\end{tabular}

migration impairs ductility and corrosion resistance, particularly in zirconium alloys. However, it is beneficial in some instances for unalloyed zirconium.

Zircaloys - The hafnium-containing commercial grades of zirconium alloys (Grade 702 and 704), and nuclear-grade alloys as Zircaloy-2 and Zircaloy-4, contain the strong $\alpha$ stabilizers tin and oxygen, plus the $\beta$ stabilizers iron, chromium, and nickel (Ni only in Zry-2). There is an extensive $\alpha+\beta$ field from about 790 to $1010^{\circ} \mathrm{C}\left(1450\right.$ to $\left.1850^{\circ} \mathrm{F}\right)$. Iron, chromium, and nickel form intermetallic compounds, and the distribution of these compound phases is critical to the corrosion resistance of the alloys in steam and hot water. These alloys are generally forged in the $\beta$ region, then solution treated at about $1065^{\circ} \mathrm{C}\left(1950^{\circ} \mathrm{F}\right)$ and water quenched. Subsequent hot working and heat treating is done in the $\alpha$ region (below $790^{\circ} \mathrm{C}$, or $1450^{\circ} \mathrm{F}$ ) to preserve the fine, uniform distribution of intermetallic compounds that results from solution treating and quenching. Except for being somewhat stronger and less ductile than unalloyed grades, the Zircaloys are quite similar to unalloyed zirconium in metallurgical behavior.

$\mathrm{Zr}$-Nb alloys - The only other zirconium alloy that has significant commercial importance is $\mathrm{Zr}-2.5 \mathrm{Nb}$. In zirconium, niobium is a mild $\beta$ stabilizer; eutectoid reaction is induced when the niobium content exceeds about $1 \%$. (The eutectoid point occurs at $20 \% \mathrm{Nb}$.) The mechanical and physical properties of $\mathrm{Zr}-2.5 \mathrm{Nb}$ are very similar to those of the Zircaloys; however, its corrosion resistance is slightly inferior to that of the Zircaloys.

Nuclear grade Zirconium-alloys were originally designed by the U.S. Naval Research Lab for nuclear propulsion of submarines. Zircaloys were developed to function in a Mark-II naval reactor that later became the design basis for pressurized water reactors (PWR). Later, Zircaloys and Zr-based alloys expanded their use into other water reactors such as boiling water reactors (BWRs), as well as in the Canadian (CANDU) and Russian (VVER and RBMK) reactor types. There is extensive information on the behavior of $\mathrm{Zr}$-alloys at low-temperature $\left(<500^{\circ} \mathrm{C}\right)$, high-pressure $(7.5-16 \mathrm{MPa})$, and water $\left(\mathrm{H}_{2} \mathrm{O}\right.$ and $\mathrm{D}_{2} \mathrm{O}$ ) environments. However, the use of nuclear grade zirconium alloys in air-cooled reactors at atmospheric pressure and higher temperatures (up to $820^{\circ} \mathrm{C}$ ), such as TREAT, are unusual, and there is relatively less information on their behavior in a significantly different service environment. Limited technical literature data and current INL testing suggest that LWR Zr-alloys (Zry-2, Zry-4, Zirlo, Zr-1Nb, and $\mathrm{Zr}-2.5 \mathrm{Nb}$ ) exhibit a notable reduction in resistance to oxidation in air environments at elevated temperature when compared to TREAT's original Zircaloy-3 clad material. However, other properties as mechanical strength, creep resistance, thermal conductivity and neutronics are comparable across the commercially available nuclear grade zirconium-based alloys [10].

\subsection{Literature Review: Zircaloy-4 Process-microstructure-properties}

\subsubsection{Time-transformation Diagrams for Zr-rich Alloys}

An extensive search throughout the technical literature for TT diagrams for Zr-based alloys was performed. However, neither the Atlas of Time-Temperature Diagrams for Nonferrous Alloys nor other sources had a concise construction of either a TTT or CCT diagram. Unfortunately, only diagrams for $\mathrm{Zr}-\mathrm{Mo}, \mathrm{Zr}-\mathrm{U}, \mathrm{Zr}-\mathrm{U}-\mathrm{H}$, and $\mathrm{Nb}-\mathrm{Zr}$ (25-33 atomic \% Zr) alloys were found [11]. Interestingly enough, there were no TT diagrams available for any of the typical Zr-based nuclear grade alloys. However, in Figure 12, the TTT diagram for Zr-1.3wt.\% Mo alloy is presented because this diagram is analogous to what can be expected for a Zircaloy-4 TTT diagram. A direct comparison can be made because Tin is in solid solution in Zirconium, both Iron $\left(<727^{\circ} \mathrm{C}\right)$ and Chromium conform a BCC phase as does Molybdenum, hence, $\alpha$-stabilizers in Zirconium. Also, their respective binary phase diagram contains a eutectoid reaction at the Zirconium-rich side, where upon cooling from $\beta \mathrm{Zr}$ form $\alpha \mathrm{Zr}$ and an intermetallic phase $\mathrm{ZrX}$ ahere $\mathrm{X}$ is Fe, Cr or Mo and $a$ is 3 for Fe and 2 for $\mathrm{Cr}$ and Mo, repectively [12-14]. 


\begin{tabular}{|c|lll|}
\hline HEAT TREATMENT DEVELOPMENT FOR & Identifier: & PLN-5403 & \\
THE TREAT LEU FUEL & Revision: & 0 & \\
ZR-ALLOY CLADDING VIA & Effective Date: & $07 / 02 / 2018$ & Page: 15 of 33 \\
TIME-TEMPERATURE DIAGRAMS & & \\
\hline
\end{tabular}

Zirconium-Molybdenum Alloys

Composition: $\mathrm{Zr}-1.3 \%$ Mo

Treatment: Forged alloy rods were held at 975 to $1000^{\circ} \mathrm{C}(1787$

to $1832^{\circ} \mathrm{F}$ ) for 15 to $30 \mathrm{~min}$, ieothermally quenched, held for a

given length of time, then rapidly water quenched

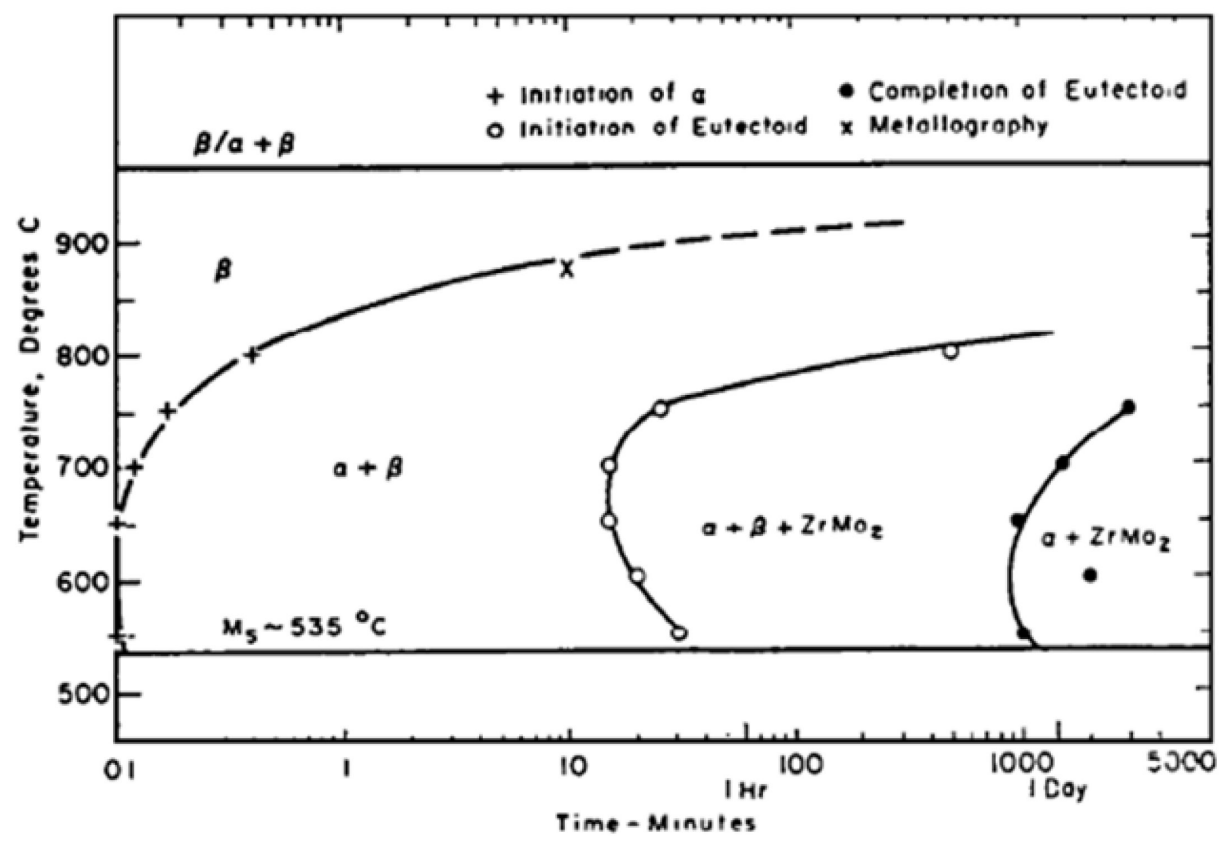

Figure 12. TTT diagram for Zirconium 1.3wt\% Molybdenum alloy [10].

Nonetheless, multiple articles were collected where the process-microstructure-properties of Zircaloy-4 material were studied. Varying plate and sheet Zry-4 materials were studied as a function of specific thermomechanical and heat treatment processes. The Zry-4 coupons' respective mechanical and corrosion properties were evaluated and correlated to their microstructure. These data will be of great value for the construction of a TT diagrams for Zircaloy-4 and to establish the process-microstructure-properties relationship. These studies are provided in the following subsections.

\subsubsection{Cold Working Effect on Mechanical Properties of Zircaloy-4}

This study illustrates the effect of cold working on the mechanical properties Zircaloy-4 plate.

Strain hardening is the phenomenon whereby a ductile metal becomes harder and stronger as it is plastically deformed. Sometimes it is also called work hardening, or, because the temperature at which deformation takes place is "cold" relative to the absolute melting temperature of the metal, cold working. Most metals strain harden at room temperature. Strain hardening is often utilized commercially to enhance the mechanical properties of metals during fabrication procedures. The effects of strain hardening may be removed by an annealing heat treatment.

Sarkar and Murty [15] investigated the evolution of microstructure and the mechanical properties of cryo-rolled Zircaloy- 4 to understand the origin of the alloy's strength processed at a cryogenic temperature. A $4.2 \mathrm{~mm}$ thick Zry-4 plate with a nominal chemical composition of $(\mathrm{Zr}-1.5 \mathrm{Sn}-0.1 \mathrm{Cr}-0.2 \mathrm{Fe})$ was used for this study. The plate was annealed at $760^{\circ} \mathrm{C}$ ( $\alpha$ annealing treatment) for $2 \mathrm{hr}$ before rolling. The annealed plate was then dipped in liquid nitrogen for 15 minutes and then from 4.2 to 3.35, 2.10 and $1.25 \mathrm{~mm}$ in different passes. These thicknesses corresponded to $20 \%, 50 \%$ and $70 \%$ reduction. To prevent 


\begin{tabular}{|c|c|c|c|}
\hline $\begin{array}{c}\text { HEAT TREATMENT DEVELOPMENT FOR } \\
\text { THE TREAT LEU FUEL } \\
\text { ZR-ALLOY CLADDING VIA } \\
\text { TIME-TEMPERATURE DIAGRAMS }\end{array}$ & $\begin{array}{l}\text { Identifier: } \\
\text { Revision: } \\
\text { Effective Date: }\end{array}$ & $\begin{array}{l}\text { PLN-5403 } \\
0 \\
07 / 02 / 2018\end{array}$ & Page: 16 of 33 \\
\hline
\end{tabular}

cracking, each thickness reduction was achieved in about 10 passes. After each pass, the plate was immersed in liquid nitrogen for over $5 \mathrm{~min}$ before the next reduction.

Figure 13(a) shows the stress-strain curves for annealed and cold worked material. Yield strength (YS), ultimate tensile strength (UTS), and percent elongation (\%EL) are also plotted in Figure 13(b). Annealed sample showed considerable work hardening and a higher ductility. YS and UTS increased by increasing the rolling reduction. Ductility or \%EL decreased with increased cold work percent.
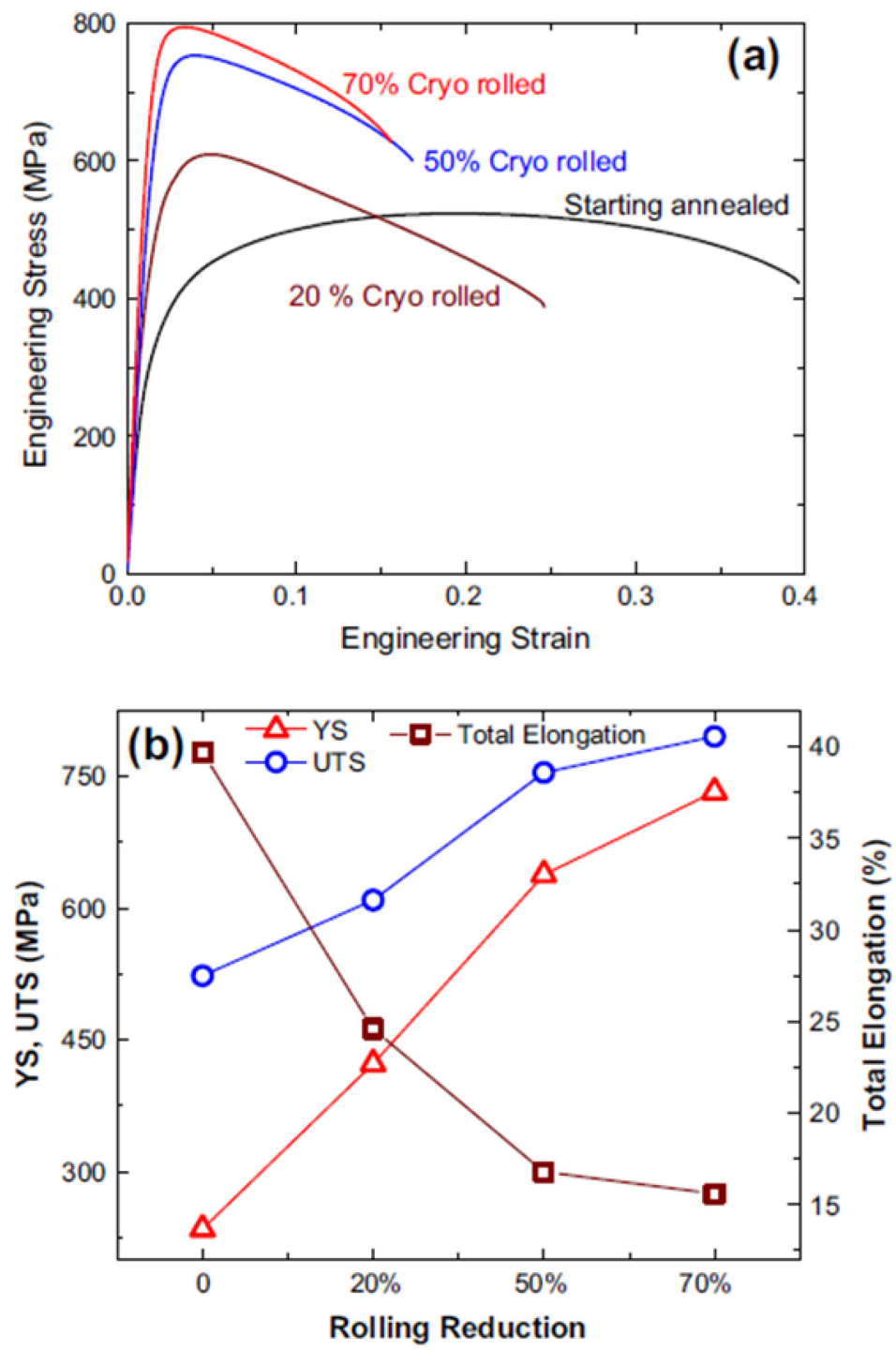

Figure 13. (a) Engineering stress-strain curves for annealed and cryo-rolled Zry-4 samples and (b) variation of YS, UTS and \%EL with rolling reduction [15].

The study adjudicated the increase in strength in the cryo-rolled sample due to an increase in dislocation density. The correlation of dislocation density, grain size, and yield stress of the rolled product indicated that an increase in dislocation density due to the suppression of dynamic recovery (close-packed crystal structures, i.e., hexagonal closed packed [HCP] and face-centered cubic [FCC] materials, have high stacking-fault energy and can continuously remove and balance the strain hardening imposed during 


\begin{tabular}{|c|lll|}
\hline HEAT TREATMENT DEVELOPMENT FOR & Identifier: & PLN-5403 & \\
THE TREAT LEU FUEL & Revision: & 0 & \\
ZR-ALLOY CLADDING VIA & Effective Date: & $07 / 02 / 2018$ & Page: 17 of $\mathbf{3 3}$ \\
TIME-TEMPERATURE DIAGRAMS & & & \\
\hline
\end{tabular}

a hot working process) is the primary source of strengthening as seen in Figure 14(a). On the other hand, the decrease in grain size results in poor work hardening as observed by the decrease in the strain hardening exponent $n$ as observed in Figure 14(b); $n$ is a measure of the ability of a metal to strain harden, the larger its magnitude, the greater the strain hardening for a given amount of plastic strain.
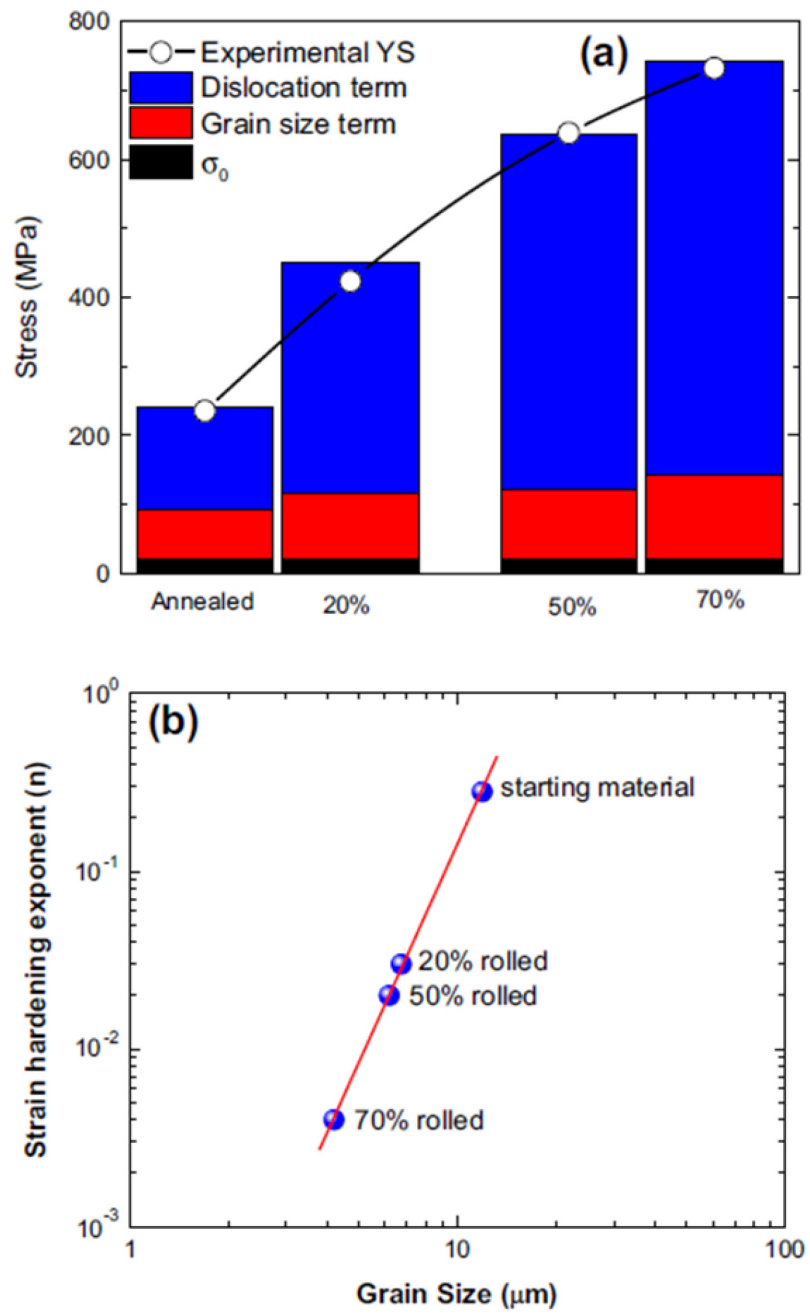

Figure 14. (a) Comparison of calculated and experimental stress and (b) variation of strain hardening exponent with grain size from cryo-rolled Zr4 samples [15]. 


\begin{tabular}{|c|lll|}
\hline HEAT TREATMENT DEVELOPMENT FOR & Identifier: & PLN-5403 & \\
THE TREAT LEU FUEL & Revision: & 0 & \\
ZR-ALLOY CLADDING VIA & Effective Date: & $07 / 02 / 2018$ & Page: 18 of 33 \\
TIME-TEMPERATURE DIAGRAMS & & & \\
\hline
\end{tabular}

\subsubsection{Thermomechanical Process and Thermal Treatment Effect on Zircaloy-4 Mechanical Properties}

This study is presented to show the effect of various processing routes on the mechanical properties of Zircaloy-4 sheet and plate material.

Bai, et al. [16] studied the hydride embrittlement in Zircaloy-4 at room temperature and $350^{\circ} \mathrm{C}$. Sheet tensile specimens of two fabrication routes in the stress-relieved (or elevated temperature recovery processed), recrystallized, and $\beta$-treated states were studied. Two Zry- 4 cold-rolled sheets of different thicknesses in three metallurgical states were used: stress-relieved $\left(460^{\circ} \mathrm{C}\right.$ for 24 hours), recrystallized $\left(650^{\circ} \mathrm{C}\right.$ for 3 hours), and beta-treated $\left(1030^{\circ} \mathrm{C}\right.$ for 2 minutes followed by air quenching). The cold-rolling ratio was $38 \%$ for the $0.5-\mathrm{mm}$ sheet and $30 \%$ for the $3.1-\mathrm{mm}$ plate. The fabrication routes were classical for the $0.5-\mathrm{mm}$ sheets (referred as $\mathrm{C} 1, \mathrm{C} 2$, and C3) and a super alpha-one for the 3.1-mm sheets (referred as S1, S2, and S3). In the classical route, the ingot was processed by successive operations of hot forging, quenching, hot rolling, and annealing, followed by several cold rolling and recrystallizing cycles down to a $0.5-\mathrm{mm}$ sheet. The corresponding microstructures and grain texture for these different metallurgical states are given in Figure 15.

\begin{tabular}{|c|c|c|c|}
\hline & & Mictrostructure & Texture (Kearn's Factors) \\
\hline \multirow{4}{*}{$0.5-\mathrm{mm}$ sheet } & $\mathrm{Cl}$ & $\begin{array}{l}\text { elongated and aligned } \alpha \text { grains in the } L-T \text { plane, } \\
\text { having an in-plane size about } 4 \times 10 \mu \mathrm{m}\end{array}$ & $\begin{array}{l}f_{N}=0.68 \\
f_{L}=0.20\{10 \overline{1} 0\} / / L \\
f_{r}=0.12\end{array}$ \\
\hline & $\mathrm{C} 2$ & ex-axial grain, with an in-plane size about $7 \times 7 \mu \mathrm{m}$ & $\begin{array}{l}f_{N}=0.65 \\
f_{L}=0.22\{11 \overline{2} 0\} / / L \\
f_{T}=0.13\end{array}$ \\
\hline & $\mathrm{C} 3$ & $\begin{array}{l}\alpha \text {-phase lamellae (about } 10 \times 125 \mu \mathrm{m} \text { ) in the big } \\
\text { prior- } \beta \text { grain; most have the same orientation } \\
\text { relationship with the matrix as have the hydrides }\end{array}$ & $\begin{array}{l}f_{N}=0.48 \\
f_{L}=0.25\{10 \overline{1} 0\} / / L \\
f_{T}=0.27\end{array}$ \\
\hline & S1 & $\begin{array}{l}\text { elongated grains and layered structures containing } \\
\text { deformed prior- } \beta \text {-phase platelets during rolling } \\
\text { (similar to cold-worked Excel of Ref. } 13 \text { in Ref. 23) }\end{array}$ & $\begin{array}{l}f_{N}=0.66 \\
f_{L}=0.23\{10 \overline{1} 0\} / / L \\
f_{r}=0.11\end{array}$ \\
\hline \multirow[t]{2}{*}{ 3.1-mm sheet } & S2 & $\begin{array}{l}\text { elongated grains and layered structures partially } \\
\text { recrystallized (similar to annealed Excel of Ref. } 13 \\
\text { in Ref. 23) }\end{array}$ & $\begin{array}{l}f_{N}=0.65 \\
f_{L}=0.24\{11 \overline{2} 0\} / / L \\
f_{r}=0.11\end{array}$ \\
\hline & S3 & similar to $\mathrm{C} 3$ & $\begin{array}{l}f_{N}=0.47 \\
f_{L}=0.25\{10 \overline{1} 0\} / / L \\
f_{T}=0.28\end{array}$ \\
\hline
\end{tabular}

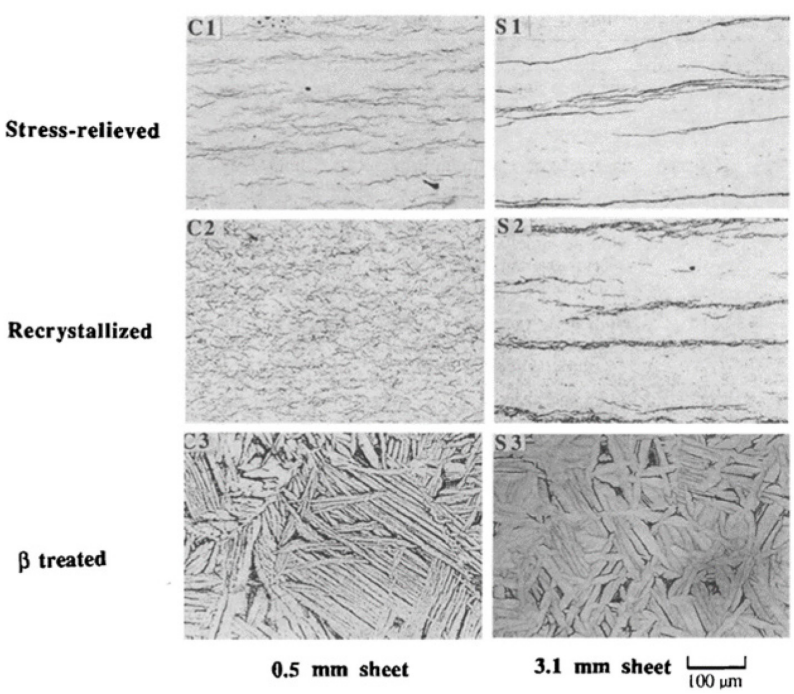

Figure 15. Processing route, microstructure and grain texture for hydrided Zry-4 [16]. 


\begin{tabular}{|c|c|c|c|}
\hline $\begin{array}{c}\text { HEAT TREATMENT DEVELOPMENT FOR } \\
\text { THE TREAT LEU FUEL } \\
\text { ZR-ALLOY CLADDING VIA } \\
\text { TIME-TEMPERATURE DIAGRAMS }\end{array}$ & $\begin{array}{l}\text { Identifier: } \\
\text { Revision: } \\
\text { Effective Date: }\end{array}$ & $\begin{array}{l}\text { PLN-5403 } \\
0 \\
07 / 02 / 2018\end{array}$ & Page: 19 of 33 \\
\hline
\end{tabular}

The following analysis will be limited to the mechanical properties for Zry-4 material with less than $25 \mathrm{ppm}$ hydrogen levels in accordance to the ASTM specifications for nuclear grade zirconium-based alloys (ASTM B350, B352, B353 and B811).

Figure 16 shows the room temperature yield strength for Zry-4 material. A 25\% higher YS for stress-relieved sheet material is observed when compared to recrystallized and $\beta$-treated material. The difference is more significant for the Zry-4 plate, where the stress-relieved material shows about $50 \%$ and $20 \%$ higher YS value than then $\beta$-treated and recrystallized plate, respectively.

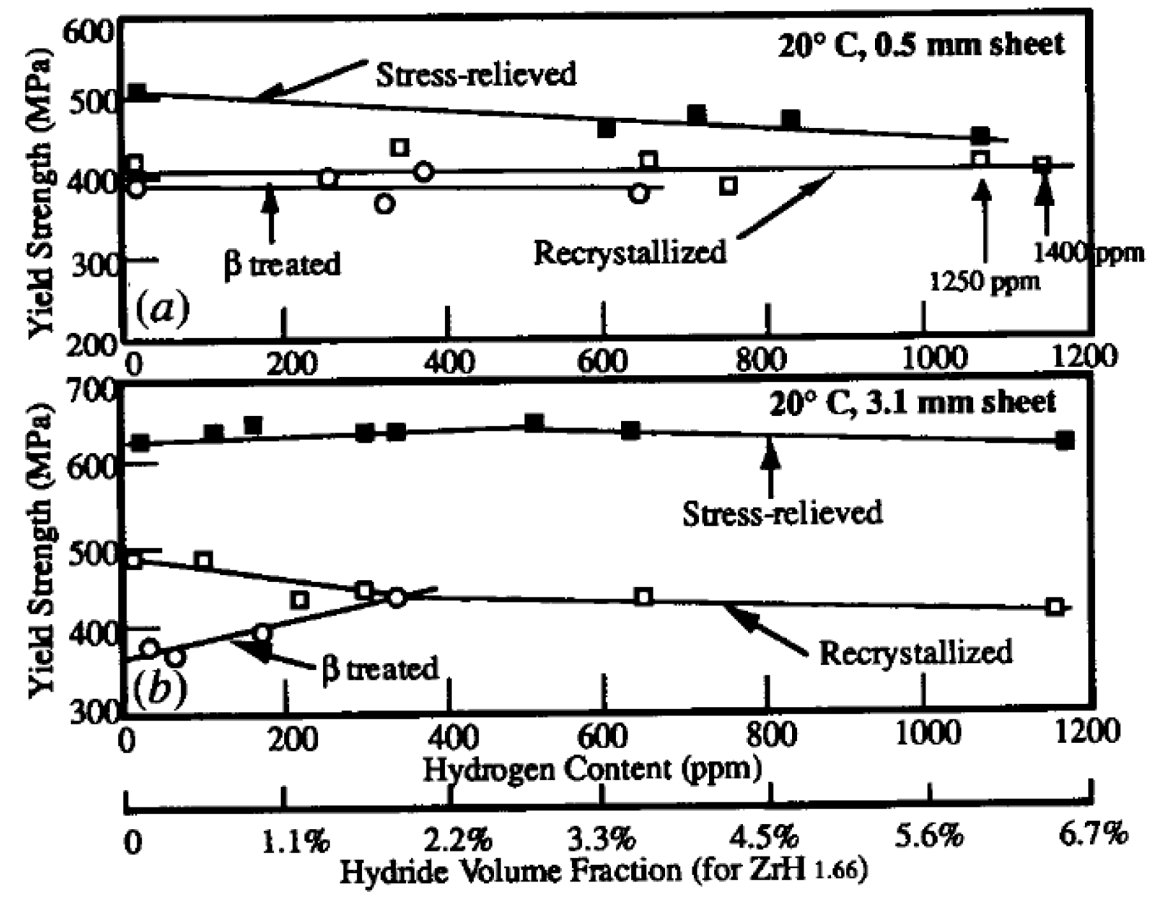

Figure 16. Influence on yield strength at $20^{\circ} \mathrm{C}$ due to different thermomechanical treatments, hydrogen content and sheet thickness [16].

Figure 17 shows the room temperature ultimate tensile strength for Zry-4 material. Over a 10\% higher UTS is observed for stress-relieved sheet material when compared to recrystallized and $\beta$-treated material. The Zry- 4 stress-relieved plate shows about $40 \%$ higher UTS than then $\beta$-treated and recrystallized plate. 


\begin{tabular}{|c|lll|}
\hline HEAT TREATMENT DEVELOPMENT FOR & Identifier: & PLN-5403 & \\
THE TREAT LEU FUEL & Revision: & 0 & \\
ZR-ALLOY CLADDING VIA & Effective Date: & $07 / 02 / 2018$ & Page: 20 of $\mathbf{3 3}$ \\
TIME-TEMPERATURE DIAGRAMS & & & \\
\hline
\end{tabular}

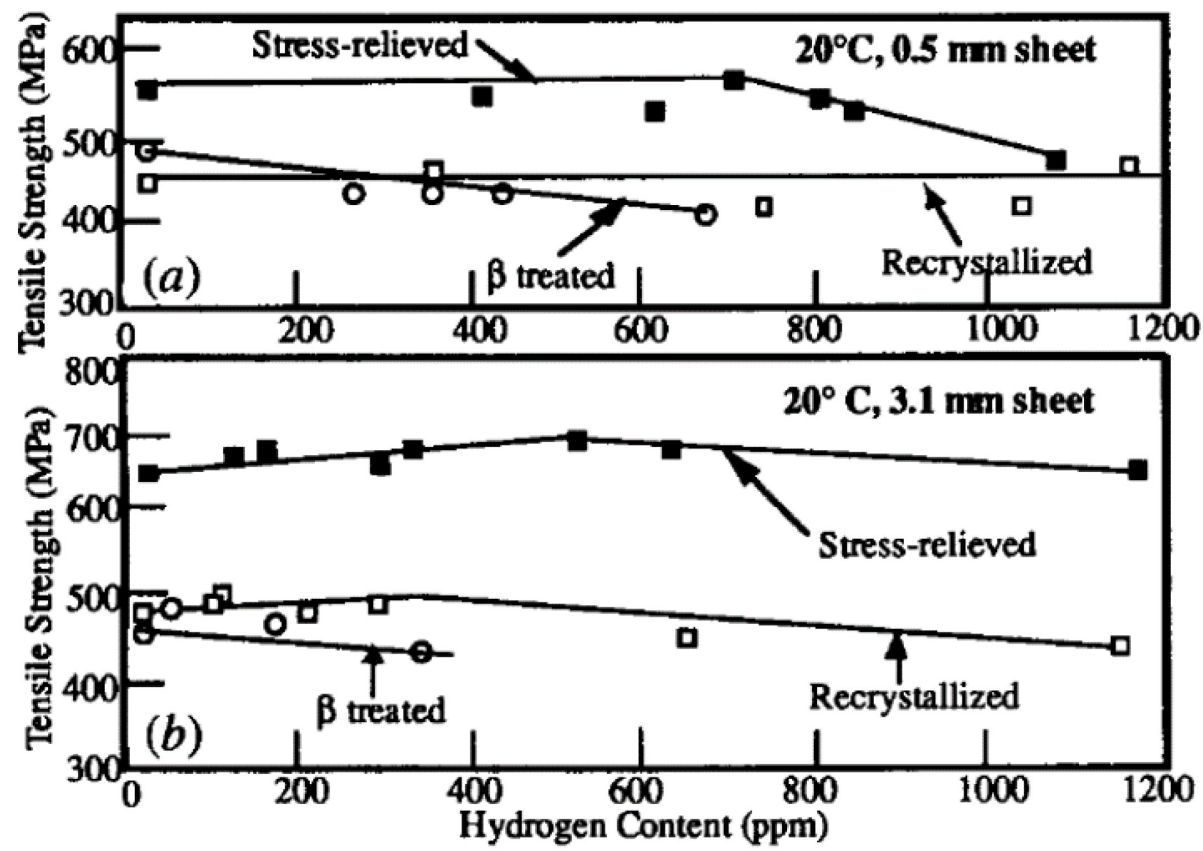

Figure 17. Influence on ultimate tensile strength at $20^{\circ} \mathrm{C}$ due to different thermomechanical treatments, hydrogen content and sheet thickness [16].

Figure 18 shows the effect of the thermomechanical treatment on the room temperature ductility of Zry-4 sheet and plate material. As expected, the recrystallized is the most ductile, followed by the stressrelieved. $\beta$-treated material shows the lowest ductility at room temperature, except for the plate $\% \mathrm{EL}$ where stress-relieved shows lower ductility. A similar pattern is observed for the $350^{\circ} \mathrm{C}$ tensile test observed in Figure 19. 


\begin{tabular}{|c|lll|}
\hline HEAT TREATMENT DEVELOPMENT FOR & Identifier: & PLN-5403 & \\
THE TREAT LEU FUEL & Revision: & 0 & \\
ZR-ALLOY CLADDING VIA & Effective Date: & $07 / 02 / 2018$ & Page: 21 of 33 \\
TIME-TEMPERATURE DIAGRAMS & & & \\
\hline
\end{tabular}
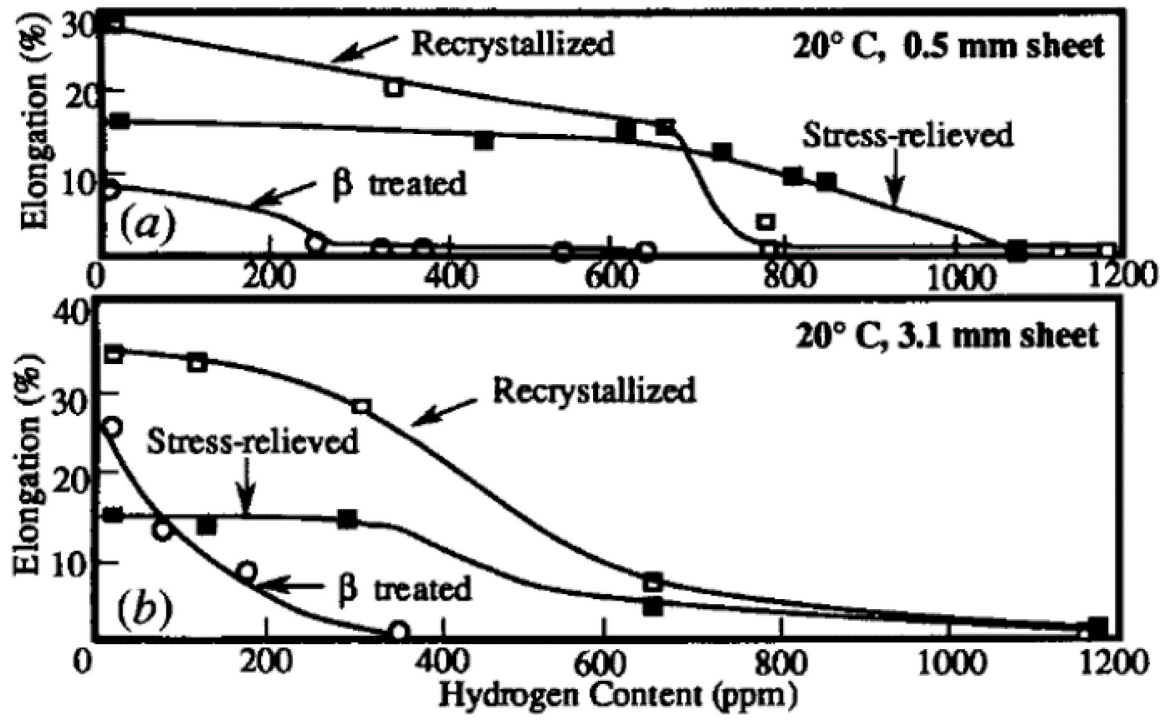

(a)
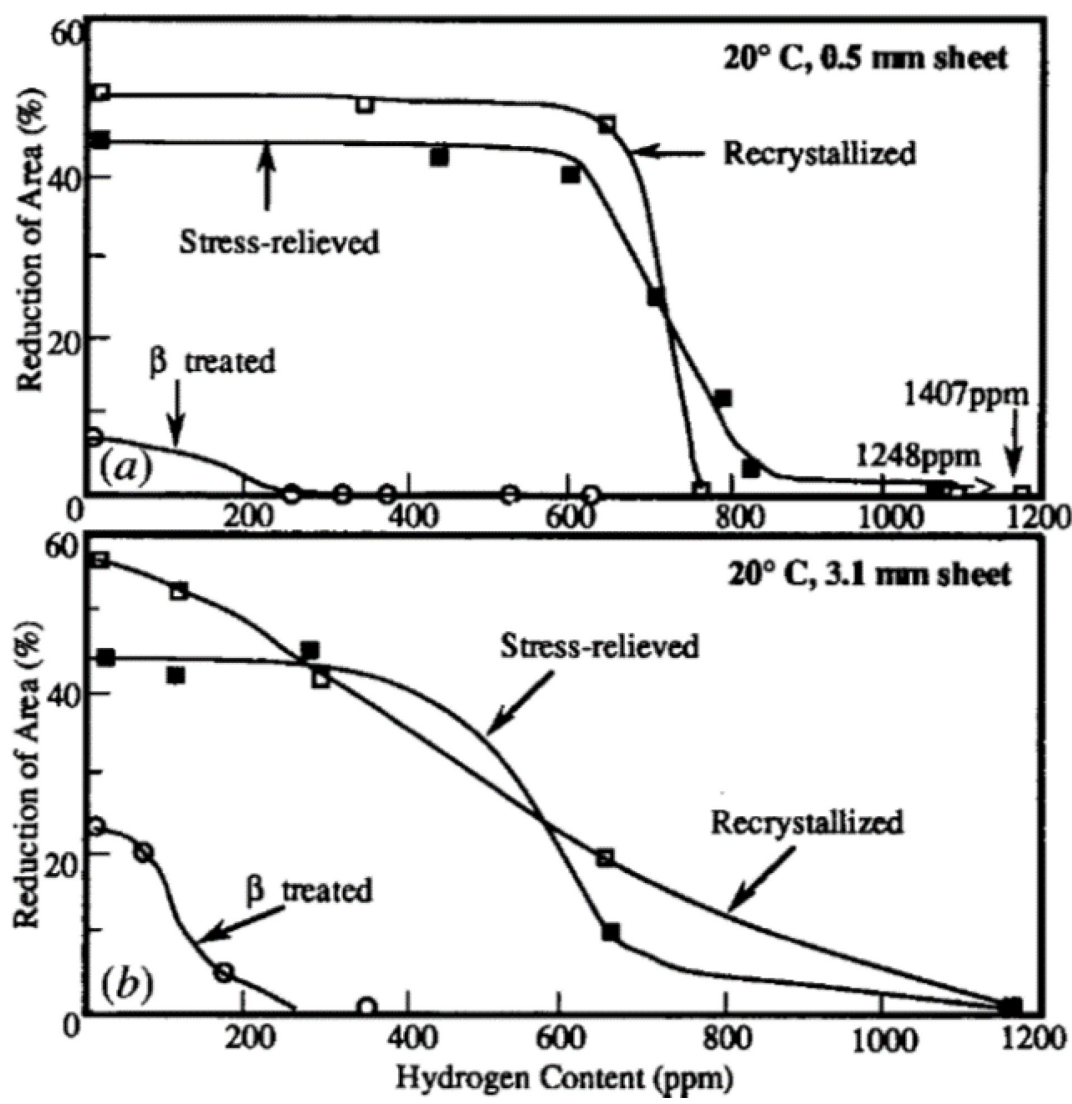

(b)

Figure 18. Influence of thermomechanical treatments, hydrogen content and sheet thickness on ductility. (a) $\%$ Elongation and (b) $\%$ reduction of area at $20^{\circ} \mathrm{C}[16]$. 


\begin{tabular}{|c|lll|}
\hline HEAT TREATMENT DEVELOPMENT FOR & Identifier: & PLN-5403 & \\
THE TREAT LEU FUEL & Revision: & 0 & \\
ZR-ALLOY CLADDING VIA & Effective Date: & $07 / 02 / 2018$ & Page: 22 of 33 \\
TIME-TEMPERATURE DIAGRAMS & & \\
\hline
\end{tabular}
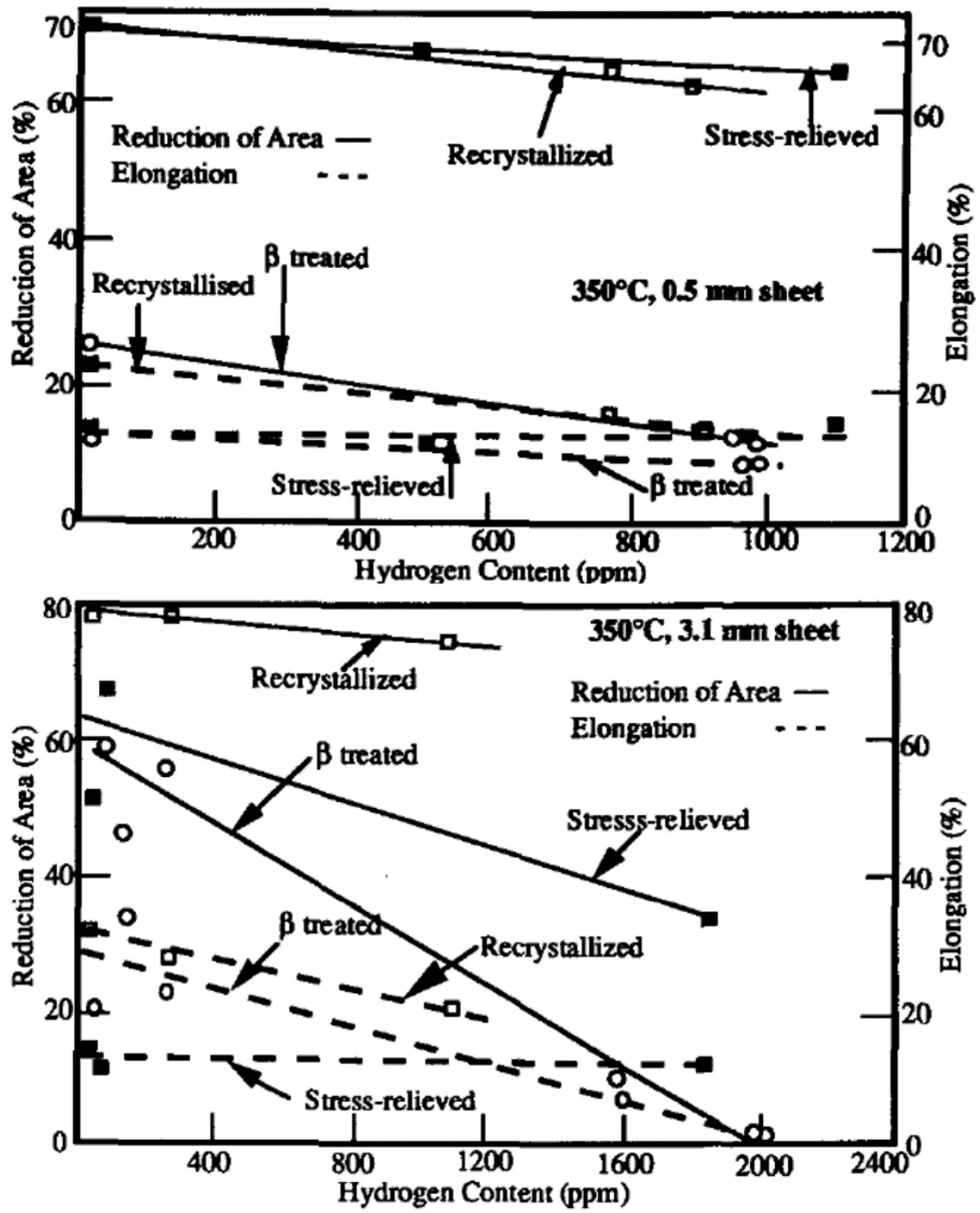

Figure 19. Influence on the ductility at $350^{\circ} \mathrm{C}$ due to different thermomechanical treatments, hydrogen content and sheet thickness [16].

This study emphasizes the differences in mechanical response observed for the same Zircaloy-4 material as a function of thermomechanical processes and material thickness.

Similarly, $\operatorname{Kim}$ [17] investigated the influence of $\beta$-heat treatment in temperatures $1,000-1,200^{\circ} \mathrm{C}$ on the microstructure and mechanical anisotropy of Zircaloy-4 fuel cladding. The tube material was manufactured to standard reactor grade specifications. Dimensions of specimen were nominally $13.08 \mathrm{~mm}$ outside diameter by $0.42 \mathrm{~mm}$ wall by $250 \mathrm{~mm}$ long. Specimens were placed inside a quartz tube and evacuated to $10^{-5}$ Torr, Induction heating was maintained for 30 seconds at temperatures of $1,000,1,050,1,100$ and $1,200^{\circ} \mathrm{C}$ with a deviation of $\pm 10^{\circ} \mathrm{C}$ along the gage length. Then specimens were allowed to cool down to room temperature. The average cooling rate was about $25^{\circ} \mathrm{C} / \mathrm{s}$.

Morphology of second phase particles and $\alpha$-grain were markedly changed by the heat treatment. Second phase particles in the as-received tubes were nearly round, and they were precipitated not only on grain boundaries but also within gains of matrix as shown in Figure 20. The size of precipitates was in 


\begin{tabular}{|c|lll|}
\hline HEAT TREATMENT DEVELOPMENT FOR & Identifier: & PLN-5403 & \\
THE TREAT LEU FUEL & Revision: & 0 & \\
ZR-ALLOY CLADDING VIA & Effective Date: & $07 / 02 / 2018$ & Page: 23 of $\mathbf{3 3}$ \\
TIME-TEMPERATURE DIAGRAMS & & & \\
\hline
\end{tabular}

between $0.03-0.2 \mu \mathrm{m}$, and the mean diameter was $0.076 \mu \mathrm{m}$. Also, they have nearly the same chemical composition of $\mathrm{Zr}(0.6 \mathrm{Fe}-0.4 \mathrm{Cr})_{2}$. The average number density of precipitates was $1.2 \mathrm{particles} / \mu \mathrm{m}^{2}$. On the other hand, second phase particles of $\beta$-heat treated specimens were mainly precipitated on grain boundaries, and the shape was plate-like. However, they were not much varied by the treatment conditions because of the constant cooling rate of $25^{\circ} \mathrm{C} / \mathrm{s}$. Heat-treated Zircaloy tubes exhibited texture changes, but the preferred orientation of grains still remained with increasing heat treatment temperatures.

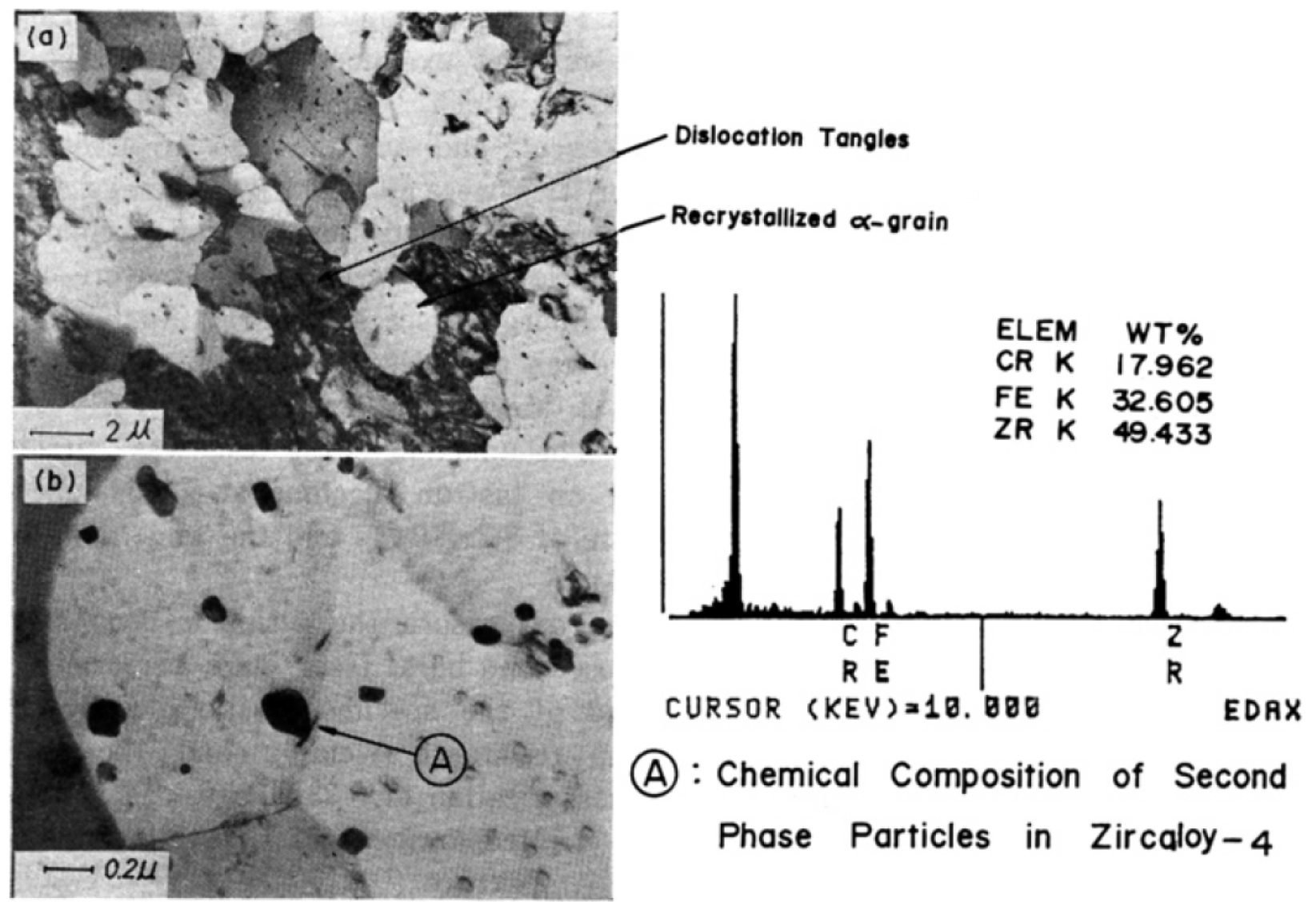

Figure 20. As-received tube microstructure showing recrystallized $\alpha$-grains and round secondary phase precipitates at grain boundaries and within grains [17]. 


\begin{tabular}{|c|lll|}
\hline HEAT TREATMENT DEVELOPMENT FOR & Identifier: & PLN-5403 & \\
THE TREAT LEU FUEL & Revision: & 0 & \\
ZR-ALLOY CLADDING VIA & Effective Date: & $07 / 02 / 2018$ & Page: 24 of $\mathbf{3 3}$ \\
TIME-TEMPERATURE DIAGRAMS & & & \\
\hline
\end{tabular}
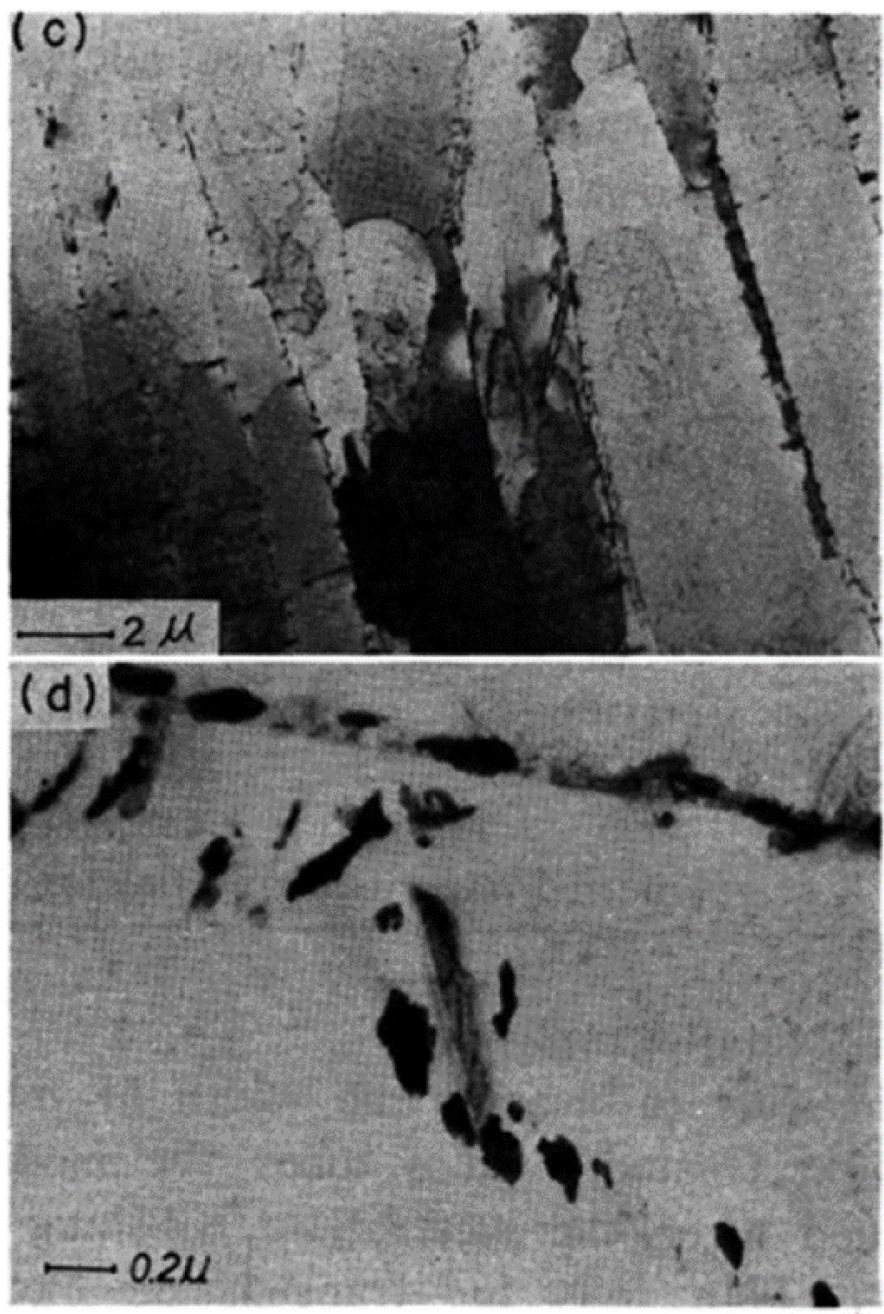

(c), (d) Heat treated tube at $1,000^{\circ} \mathrm{C}$

Figure $21 . \beta$-treated sample $\left(1000^{\circ} \mathrm{C}\right)$ showing typical microstructure with recrystallized elongated $\alpha$-grains non-uniform secondary phase precipitates at grain boundaries [17].

As observed in Figure 21, the yield strength decreased as the $\beta$-treatment temperature increased and grain grew larger; however, the grain texture and $\alpha$-plate width variations did not impact the hoop strength.

This study emphasizes the importance of the selection of an appropriate heat treatment to produce the desired microstructure with the optimum mechanical properties. 


\begin{tabular}{|c|c|c|c|}
\hline $\begin{array}{c}\text { HEAT TREATMENT DEVELOPMENT FOR } \\
\text { THE TREAT LEU FUEL } \\
\text { ZR-ALLOY CLADDING VIA } \\
\text { TIME-TEMPERATURE DIAGRAMS }\end{array}$ & $\begin{array}{l}\text { Identifier: } \\
\text { Revision: } \\
\text { Effective Date: }\end{array}$ & $\begin{array}{l}\text { PLN-5403 } \\
0 \\
07 / 02 / 2018\end{array}$ & Page: 25 of $\mathbf{3 3}$ \\
\hline
\end{tabular}

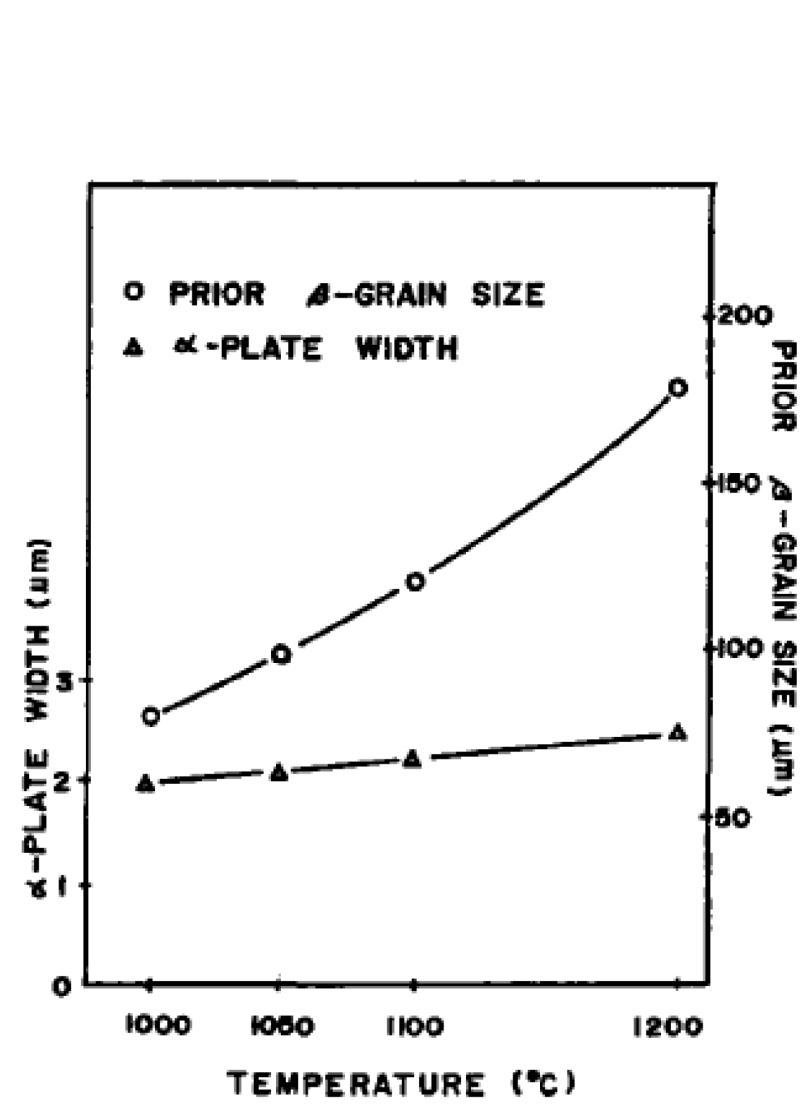

(a)

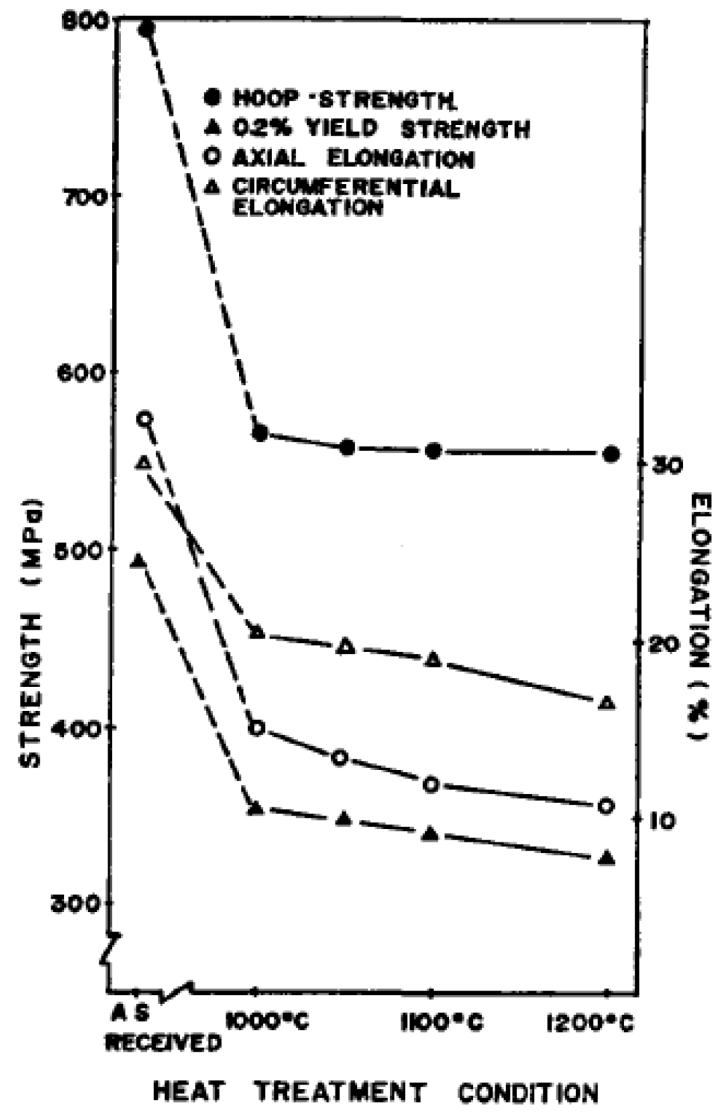

(b)

Figure 22. (a) Variation of $\alpha$-plate width and prior $\beta$-grain size and (b) ductility, yield and hoop strength as a function of heat treatment temperature [17].

\subsubsection{Heat Treatment Effect on Microstructure and Zircaloy-4 Corrosion}

Bangaru [18] investigated the microstructure and microchemistry of commercial Zircaloy-4 samples subjected to three different final heat treatments to understand the processing-microstructure-corrosion relationships in these alloys. Pronounced differences in the volume fraction, morphology, and chemistry of the intermetallic particles as well as in the $\alpha$-phase microstructure have been observed among the $\beta$-quenched, as-received (stress-relieved) and $\alpha$-annealed samples.

Table 1 has an overall summary of the microstructural and microchemical differences observed for the different heat treatments. The beta-quenched sample exhibits the most uniform microstructure consisting of acicular $\alpha$ phase with lath boundary Sn enrichment and fine intermetallic particle formation. The as-received sample has the most inhomogeneous microstructure made up of annealed and deformed a phases. 
Idaho National Laboratory

\begin{tabular}{|c|lll|}
\hline HEAT TREATMENT DEVELOPMENT FOR & Identifier: & PLN-5403 & \\
THE TREAT LEU FUEL & Revision: & 0 & \\
ZR-ALLOY CLADDING VIA & Effective Date: & $07 / 02 / 2018$ & Page: 26 of 33 \\
TIME-TEMPERATURE DIAGRAMS & & & \\
\hline
\end{tabular}

Table 1. Microstructure and microchemistry of Zircaloy-4 as a function of heat treatment [18].

\begin{tabular}{|c|c|c|c|}
\hline & Beta-quenched & As-received & Alpha-annealed \\
\hline Matrix microstructure: & $\begin{array}{l}\text { Most uniform- } \\
\text { acicular } \alpha \text { phase }\end{array}$ & $\begin{array}{l}\text { Two phases } \\
\text { Annealed } \alpha \text { (major) } \\
\text { - Deformed } \alpha \text { (minor) }\end{array}$ & $\begin{array}{l}\text { Single phase } \\
\text { recovered } \alpha\end{array}$ \\
\hline Matrix microchemistry: & $\begin{array}{l}\text { Sn conc. higher } \\
\text { at g.b. }\end{array}$ & $\begin{array}{l}\text { High solute conc. } \\
\text { in deformed } \alpha\end{array}$ & $\begin{array}{l}\text { Uniform solute } \\
\text { conc. }\end{array}$ \\
\hline $\begin{array}{l}\text { Intermetallic particle } \\
\text { volume fraction }\end{array}$ & Lowest & Intermediate & Highest \\
\hline $\begin{array}{l}\text { Intermetallic particle } \\
\text { diameter (nm) } \\
\text { Intermetallic particle }\end{array}$ & $20-25$ & $250-300$ & $\begin{array}{l}300-500 \\
70-140\end{array}$ \\
\hline chemistry ${ }^{\text {a) }}$ & $\mathrm{A}_{2} \mathrm{~B}-\mathrm{AB}_{2}-\underline{-\mathrm{AB}_{3}}$ & $\mathrm{~A}_{2} \mathrm{~B}-\mathrm{A}_{3} \mathrm{~B}_{2}-\mathrm{AB}_{2}-\mathrm{AB}_{3}$ & $\mathrm{~A}_{2} \mathrm{~B}-\mathrm{A}_{3} \mathbf{B}_{2}-\mathrm{AB}_{2}-\mathrm{AB}_{3}$ \\
\hline
\end{tabular}

a) $\mathrm{A}=\mathrm{Zr} ; \mathrm{B}=\mathrm{Fe}, \mathrm{Cr}$; predominant particles are underlined.

Figure 23 shows an illustration of the microstructural features corresponding to different thermal treatments and their relation to the nodular corrosion rate. The presence of coarse intermetallic particles increases the susceptibility to nodular corrosion. Increased volume fraction of intermetallic particles appears to increase the corrosion susceptibility. The $\alpha$-annealed sample, which displays the highest volume fraction and coarsest intermetallic particles, is the worst case for corrosion resistance. The $\beta$-quenched sample has no coarse particles. The unique fine precipitate network at the interlath boundaries in the $\beta$-quenched sample is innocuous to nodular corrosion. The Sn-rich matrix phase enveloping these particles might act to negate any harmful effects of these fine particles. The coarse intermetallic particles are not the ideal distribution as they become detached from the metal at certain oxide thickness, at which time rapid corrosion kinetics set in. A continuous network of intermetallic particles, such as the one found in the $\beta$-quenched sample, is beneficial to oxidation resistance. However, the intermetallic particle microchemistry also plays a role on the oxidation resistance. It can be observed that the presence of $\mathrm{A}_{3} \mathrm{~B}_{2}$ type phase degrades the corrosion resistance.

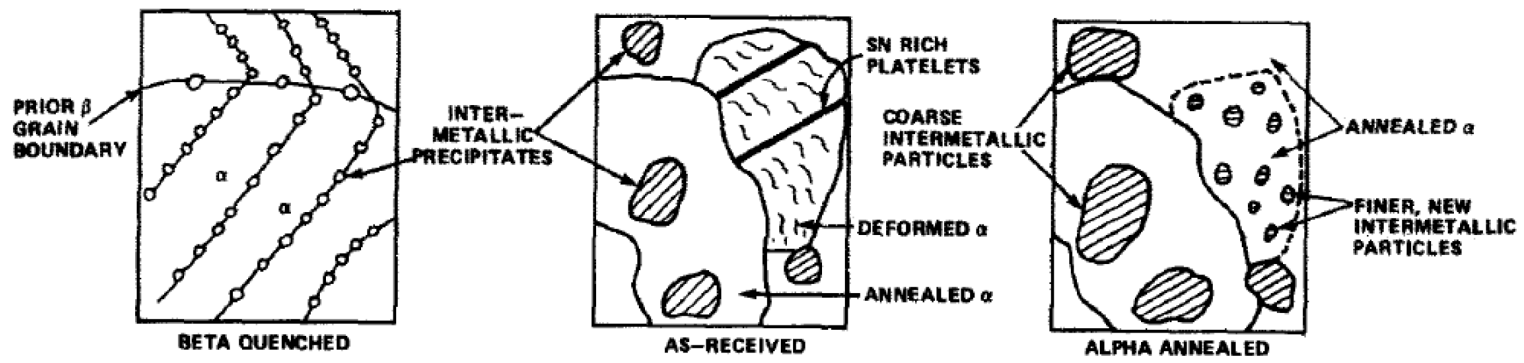

NODULAR

CORROSION

LOW

HIGH

HIGHEST

SUSCEPTIBILITY

Figure 23. Microstructure - nodular corrosion relationship as a function of heat treatment [18].

Jeong et al. [18] investigated the effect of $\beta$-heat treatment on microstructure and nodular corrosion of Zircaloy-4 for specimens that were $\beta$-heat treated and then cooled in various cooling processes, such as, iced brine $\left(2,100^{\circ} \mathrm{C} / \mathrm{s}\right)$, water $\left(1,200^{\circ} \mathrm{C} / \mathrm{s}\right)$, oil $\left(110^{\circ} \mathrm{C} / \mathrm{s}\right)$, air $\left(3.6^{\circ} \mathrm{C} / \mathrm{s}\right)$, and furnace cooling $\left(0.05^{\circ} \mathrm{C} / \mathrm{s}\right)$. 
Idaho National Laboratory

\begin{tabular}{|c|lll|}
\hline HEAT TREATMENT DEVELOPMENT FOR & Identifier: & PLN-5403 & \\
THE TREAT LEU FUEL & Revision: & 0 & \\
ZR-ALLOY CLADDING VIA & Effective Date: & $07 / 02 / 2018$ & Page: 27 of $\mathbf{3 3}$ \\
TIME-TEMPERATURE DIAGRAMS & & & \\
\hline
\end{tabular}

Cooling rate-microstructure relationship - The specimens used in this study were $2.1 \mathrm{~mm}$ thick sheets of recrystallized Zircaloy-4. The Zircaloy-4 sheets were heat treated in a vertical tube furnace at $1,050^{\circ} \mathrm{C}$ for $15 \mathrm{~min}$. It was observed that the martensitic structure with substructures of dislocations as well as twins is formed at the cooling rate of $2,100^{\circ} \mathrm{C} / \mathrm{s}$. At the cooling rate of $1,200^{\circ} \mathrm{C} / \mathrm{s}$, the classical Widmanstätten structure appears with dense dislocations in a lath and precipitates along the lath boundary. The transformation in the water-quenched specimens was suggested to take place by both diffusion and diffusionless transformation process. Table 2 contains grain size information for the phases and volume fraction of secondary phase for different cooling rates.

Microstructure-Corrosion relationship - The nodular corrosion behavior was investigated in steam at $500^{\circ} \mathrm{C}$ and $10.3 \mathrm{MPa}$. The corrosion resistance of the $\beta$ quenched specimens decreased with the decrease in the cooling rate, so that the furnace-cooled specimens exhibit the worst corrosion resistance, resulting in nodular corrosion. The corrosion of the furnace-cooled specimen progressed mostly in the interior of the grain where alloying elements of $\mathrm{Fe}$ and $\mathrm{Cr}$ were largely depleted during the slow cooling process. However, the grain boundary has revealed relatively high corrosion resistance due to higher concentration of the alloying elements. The microstructural characterization leads to the conclusion that the nucleation of nodules can be related with depletion of alloying elements of Fe and Cr. Figure 24 shows the corrosion results (weight gain) as a function of heat treatment (cooling rate from $\beta$-temperature). Figure 25 shows photographs of the samples appearance after the corrosion testing. Nodular corrosion is more prominent in slowly cooled samples.

Table 2. Microstructure of Zircaloy-4 as a function of cooling rate from $\beta$-phase treatment temperature $\left(1,050^{\circ} \mathrm{C}\right.$ for 15 mins. $)$ [19].

\begin{tabular}{cccccc}
\hline Cooling rate & $\begin{array}{c}\text { Ice brine quenched } \\
\left(2,100^{\circ} \mathrm{C} / \mathrm{s}\right)\end{array}$ & $\begin{array}{c}\text { Water quenched } \\
\left(1,200^{\circ} \mathrm{C} / \mathrm{s}\right)\end{array}$ & $\begin{array}{c}\text { Oil quenched } \\
\left(110^{\circ} \mathrm{C} / \mathrm{s}\right)\end{array}$ & $\begin{array}{c}\text { Air cooled } \\
\left(3.6^{\circ} \mathrm{C} / \mathrm{s}\right)\end{array}$ & $\begin{array}{c}\text { Furnace cooled } \\
\left(0.05^{\circ} \mathrm{C} / \mathrm{s}\right)\end{array}$ \\
$\begin{array}{c}\text { Mean } \alpha \text {-lath } \\
\text { width }(\mu \mathrm{m})\end{array}$ & 0.38 & 0.5 & 1.0 & 3.8 & 8.9 \\
\hline
\end{tabular}

Table 2 Mean diameter of precipitate and volume fraction of precipitate varying with cooling rate in Zircaloy-4 alloy

\begin{tabular}{ccccc}
\hline \multicolumn{1}{c}{ Cooling rate } & $\begin{array}{c}\text { Water quenched } \\
\left(1,200^{\circ} \mathrm{C} / \mathrm{s}\right)\end{array}$ & $\begin{array}{c}\text { Oil quenched } \\
\left(110^{\circ} \mathrm{C} / \mathrm{s}\right)\end{array}$ & $\begin{array}{c}\text { Air cooled } \\
\left(3.6^{\circ} \mathrm{C} / \mathrm{s}\right)\end{array}$ & $\begin{array}{c}\text { Furnace cooled } \\
\left(0.05^{\circ} \mathrm{C} / \mathrm{s}\right)\end{array}$ \\
Mean diameter $(\mu \mathrm{m})$ & 0.024 & 0.051 & 0.15 & 0.31 \\
Volume fraction $(\%)$ & 2.23 & 2.91 & 3.28 & 5.30 \\
\hline
\end{tabular}




\begin{tabular}{|c|lll|}
\hline HEAT TREATMENT DEVELOPMENT FOR & Identifier: & PLN-5403 & \\
THE TREAT LEU FUEL & Revision: & 0 & \\
ZR-ALLOY CLADDING VIA & Effective Date: & $07 / 02 / 2018$ & Page: 28 of $\mathbf{3 3}$ \\
TIME-TEMPERATURE DIAGRAMS & & & \\
\hline
\end{tabular}

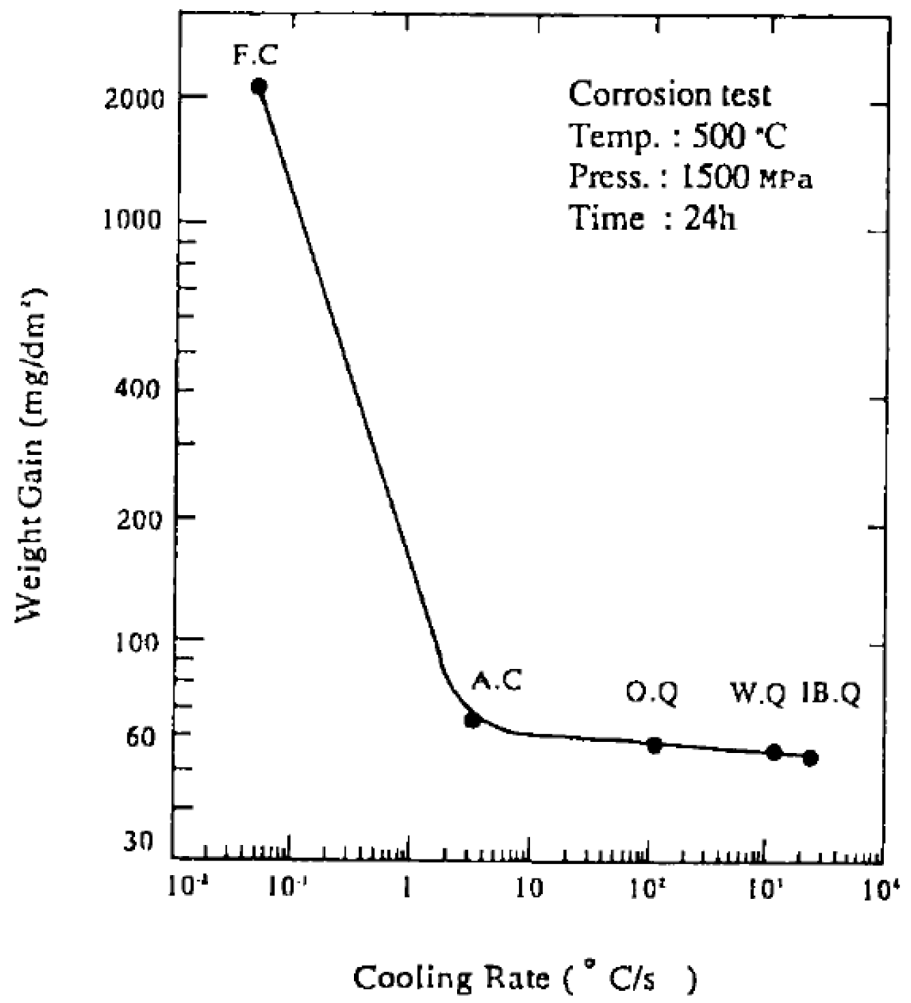

Figure 24. Zry-4 Corrosion test: weight gain as a function of cooling rate from $\beta$-treatment [19].

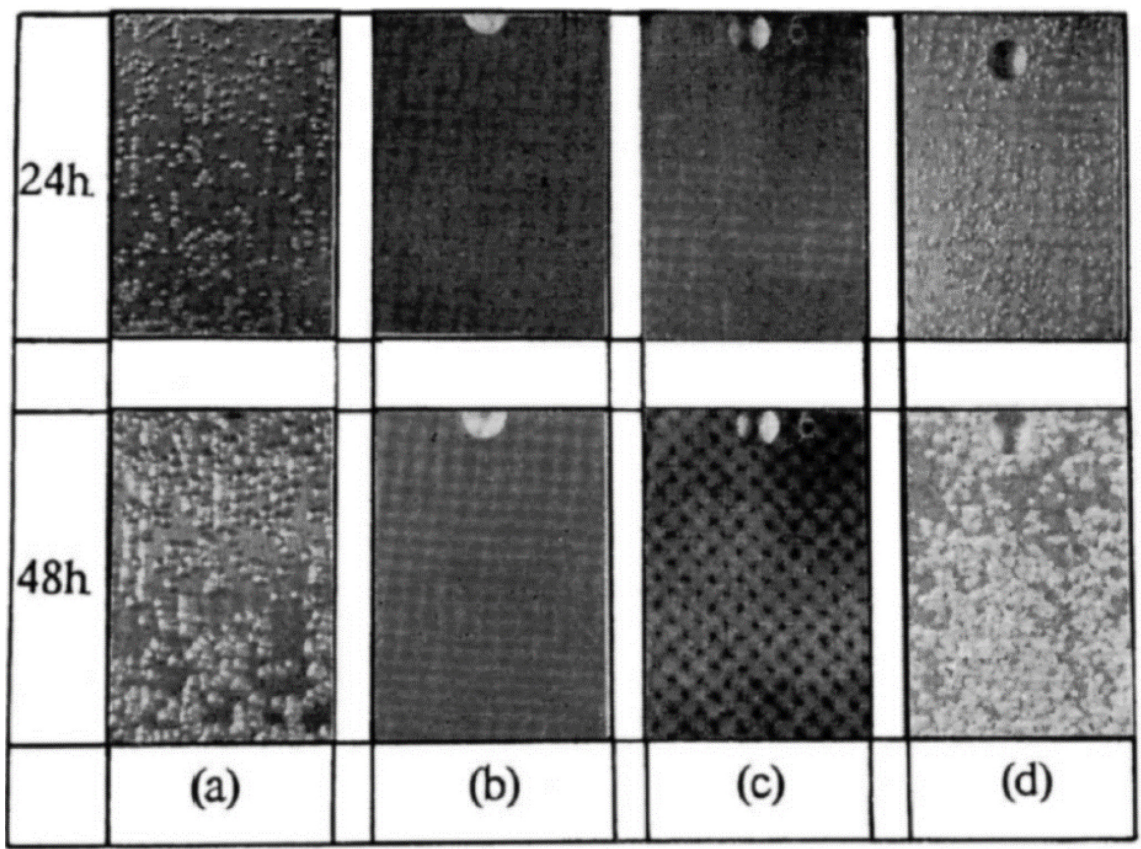

Figure 25. Samples showing nodules after $500^{\circ} \mathrm{C}$ corrosion test for 24 and 48 hours for (a) as-received, (b) water-quenched, (c) air-cooled, and (d) furnace-cooled samples [19]. 


\begin{tabular}{|c|lll|}
\hline $\begin{array}{c}\text { HEAT TREATMENT DEVELOPMENT FOR } \\
\text { THE TREAT LEU FUEL }\end{array}$ & Identifier: & PLN-5403 & \\
ZR-ALLOY CLADDING VIA & Revision: & 0 & \\
TIME-TEMPERATURE DIAGRAMS & Effective Date: & $07 / 02 / 2018$ & Page: 29 of 33 \\
\hline
\end{tabular}

\section{DEVELOPMENT OF HEAT TREATMENT FOR ZIRCALOY-4}

The impact of thermomechanical processes and heat treatments on the microstructure and properties of a material has been emphasized in the review section. The selection of an adequate metallurgical process is critical for the optimization of the material's behavior for a specific service environment.

The careful selection of an appropriate thermomechanical process and heat treatment will dictate the mechanical robustness, thermal conductivity, creep, and oxidation resistance of the TREAT LEU fuel cladding alloy. In particular, this is of great importance because the projected service life of the fuel core is a minimum of 40 years.

The development of Time Temperature diagrams will not only provide information on what is the most preferred heat treatment path, but will also permit the prediction of microstructural changes throughout the service life of the cladding and the inherent impact on its properties and performance.

\subsection{Time Temperature diagram development for Zircaloy-4}

Zr-based matrix may be either in alpha- or beta-form (different crystalline lattices - HCP [alpha] up to $863^{\circ} \mathrm{C}$ in pure $\mathrm{Zr}$, where it transforms to the $\mathrm{BCC}$ [beta-zirconium] form).

Different compounds of zirconium and alloying elements are precipitated in the matrix during thermal treatments. Some may be desirable: intermetallic $\mathrm{Zr}_{2} \mathrm{Fe}$ and $\mathrm{Zr}(\mathrm{Cr}, \mathrm{Fe})_{2}$. The reason for developing a heat treatment procedure around these intermetallics is that we know from the literature that they affect corrosion of Zry-4. Among undesirable compounds are: $\mathrm{Zr}_{3} \mathrm{Fe}$ (sharp needles that deteriorate mechanical properties), $\mathrm{Zr}_{7} \mathrm{FeSn}_{2}$, and potentially $\mathrm{Zr}_{4} \mathrm{Sn}$.

The goal is to develop an oxidation-protecting temper that also provides the most adequate mechanical, creep, and thermal properties. The careful selection of the heat treatment will dictate the location of the nucleation of secondary intermetallic phases in the alpha-matrix. The most desirable is to have a combination of grain boundary fine round precipitates but also the formation of some precipitates inside the alpha-grain laths. A careful treatment will provide the desired volume fraction of secondary phase at the desired locations in the microstructure.

It is important to note that corrosion of Zyr-4 was mostly studied for LWRs, and scarcely for air-cooled environments such as TREAT. Therefore, we need a thermodynamic study that will specifically tell us how all these phases and the matrix will interact, at different temperatures, with the air that is used for cooling TREAT components, to determine which phases are favorable for oxidation passivation.

Section 3.1.2 described the importance and valuable information that can be obtained from TTT and CCT diagrams to define the thermal processing of an alloy. Experimentally a Time Temperature diagram can be constructed by thermal treatments that explore the equilibrium structures as a function of time and temperature. A TTT diagram can be constructed by annealing a series of samples isothermally for a definite time in incremental fashion i.e. annealing at $800^{\circ} \mathrm{C}$ for $1 \mathrm{~h}, 10 \mathrm{~h} 100 \mathrm{~h}, 1000 \mathrm{~h}$, etc., and then rapidly quench the sample to freeze the equilibrium microstructure. Extra annealing treatments at intermediate times and temperature should be performed in order to define the limits of critical phase regions in the TTT diagram, for example to delineate precisely where the TTT diagram nose is located. A subsequent microstructural analysis is performed with an optical (for macro-micro features) and electron microscope (for finer features) to characterize the phases present (main matrix phase, secondary phases and precipitates) to get information as composition, relative proportion, phase morphology an the location of precipitation of precipitates in the grain structure. It is recommended to then use XRD technique to corroborate the SEM results. 


\begin{tabular}{|c|lll|}
\hline HEAT TREATMENT DEVELOPMENT FOR & Identifier: & PLN-5403 & \\
THE TREAT LEU FUEL & Revision: & 0 & \\
ZR-ALLOY CLADDING VIA & Effective Date: & $07 / 02 / 2018$ & Page: 30 of $\mathbf{3 3}$ \\
TIME-TEMPERATURE DIAGRAMS & & & \\
\hline
\end{tabular}

Construction of a CCT diagram is similar to the TTT diagram, however, a CCT diagram, as the name implies, must be constructed by subjecting a series of samples to a range of cooling rates from a starting temperature and then analyze the microstructure of the samples as previously described for TTT. One sample per cooling condition and starting temperature must be used, i.e. heat sample to $800^{\circ} \mathrm{C}$ let thermal equilibrium be achieved and cool down at $0.1^{\circ} \mathrm{C} / \mathrm{s}, 1^{\circ} \mathrm{C} / \mathrm{s}, 10^{\circ} \mathrm{C} / \mathrm{s}, 100^{\circ} \mathrm{C} / \mathrm{s}, 1,000^{\circ} \mathrm{C} / \mathrm{s}$, etc. An alternative technique to facilitate the the construction of $\mathrm{CCT}$ diagram is via the use of differential scanning calorimetry (DSC). DSC will allow the in situ detection of phase transformation that take place during the cooling of the sample. By measuring the heat capacity of the sample as it is being cooled the heat of transformation for microstructural phase changes can be detected in the form of exothermic or endothermic reactions that show up as peaks or some form of fluctuations in the curve heat flux of the sample relative to the reference sample.

Computer modeling can be used to support the development of time-temperature diagrams, however, the diagrams must always be constructed from experimental tests primarily, because the modeling is only as good as the experimental data available and important features may be neglected. For example, preliminary computer simulations performed by Dr. Michael Glazoff (INL - Materials Science and Engineering) have shown that, after casting Zyr-4, a homogenization heat treatment must be developed such that the micro-segregation of the alloying elements is avoided. Figure 26 shows that any intergranular micro-segregation will be eliminated if the alloy is isothermally heat-treated at $1100^{\circ} \mathrm{C}$ for $1 \mathrm{hr}$ and 20 minutes. Increasing the annealing time to over 6 hours does not result in any significant changes compared to $1 \mathrm{hr}$ and 20 minutes. Then a cooling path must be selected (see Figure 27) for the formation of alpha phase and secondary phases at desired locations.

Homogenisation

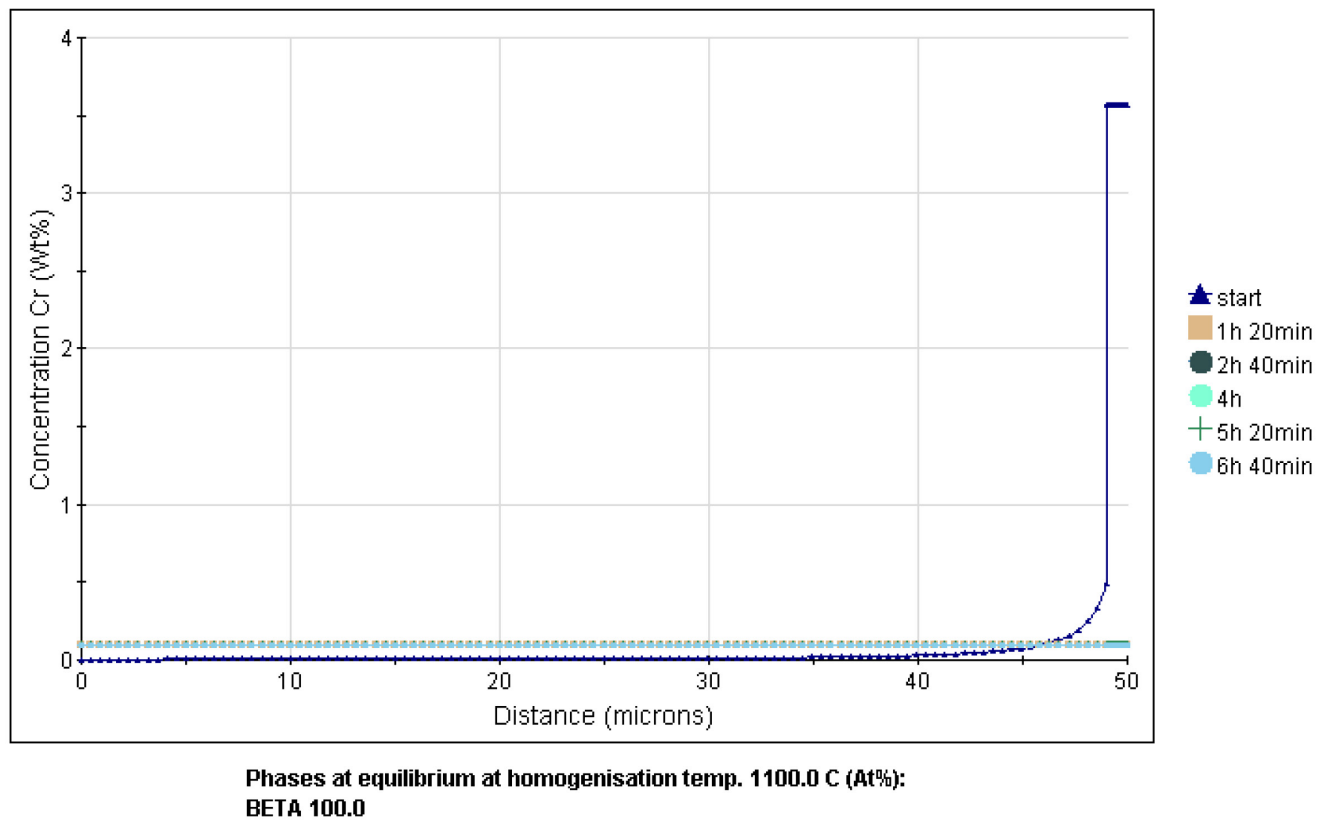

Figure 26. Preliminary simulations on the concentration of $\mathrm{Cr}$ during $\beta$-treatment for Zircaloy-4. 


\begin{tabular}{|c|lll|}
\hline HEAT TREATMENT DEVELOPMENT FOR & Identifier: & PLN-5403 & \\
THE TREAT LEU FUEL & Revision: & 0 & \\
ZR-ALLOY CLADDING VIA & Effective Date: & $07 / 02 / 2018$ & Page: 31 of $\mathbf{3 3}$ \\
TIME-TEMPERATURE DIAGRAMS & & & \\
\hline
\end{tabular}

\section{TTT Zirconium Alloy}

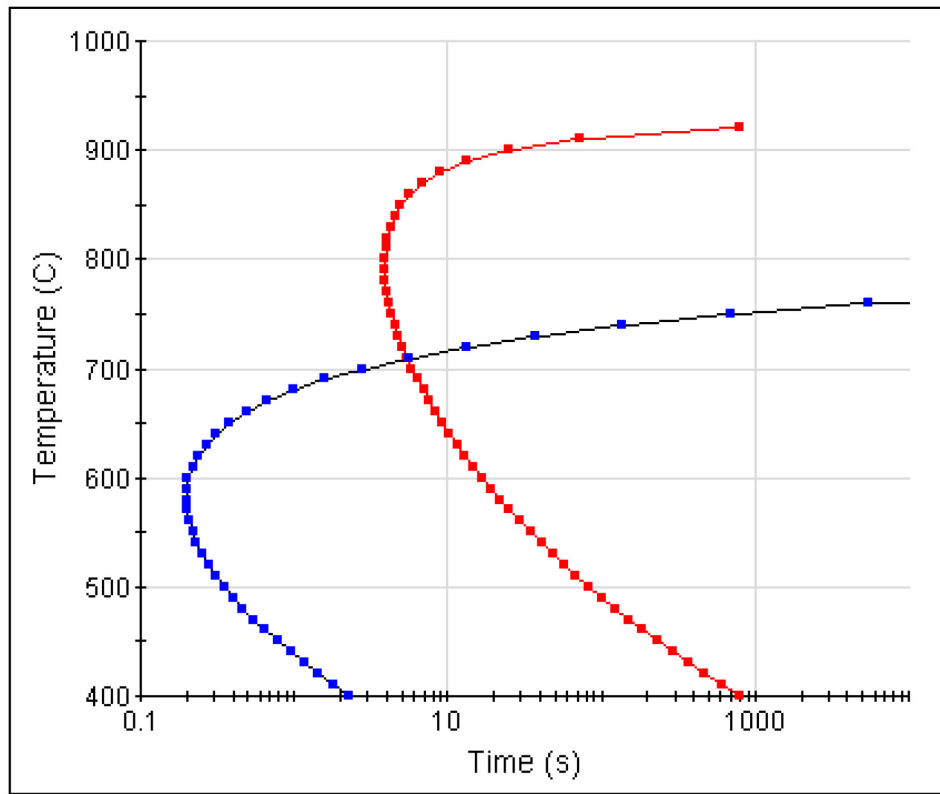

Grain size : 4.5 AGTM

CCT Zirconium Alloy

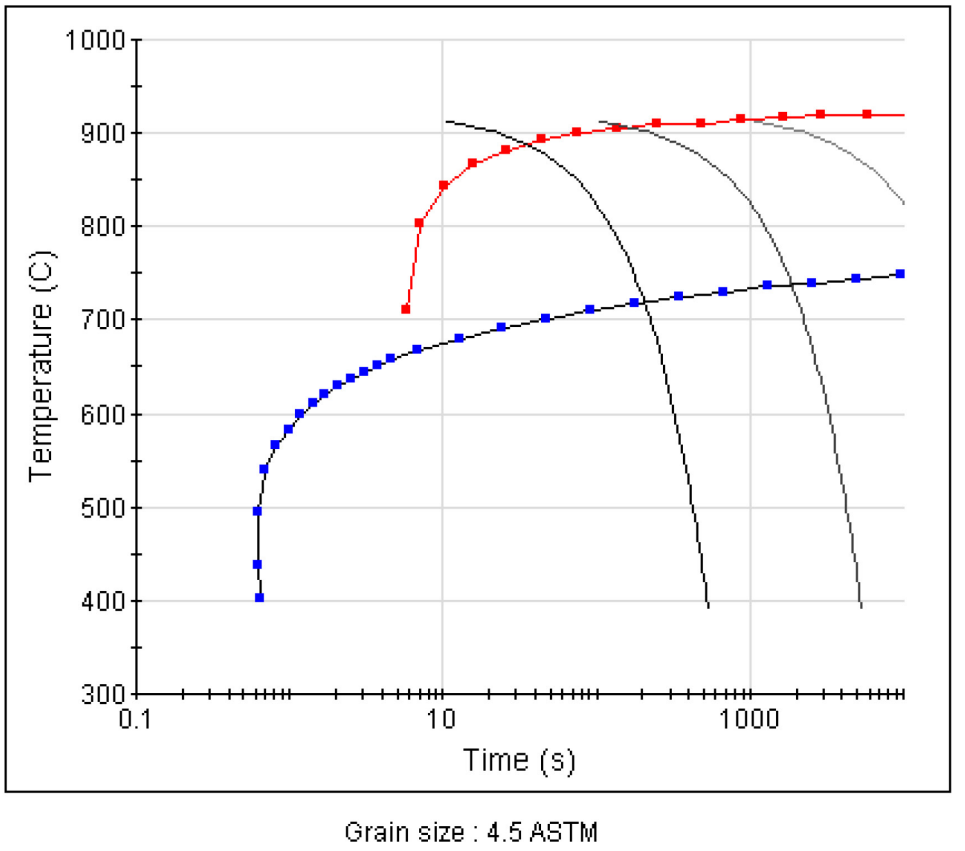

ALPHA GB(0.5\%)

ALPHA MATRIX(0.5\%)

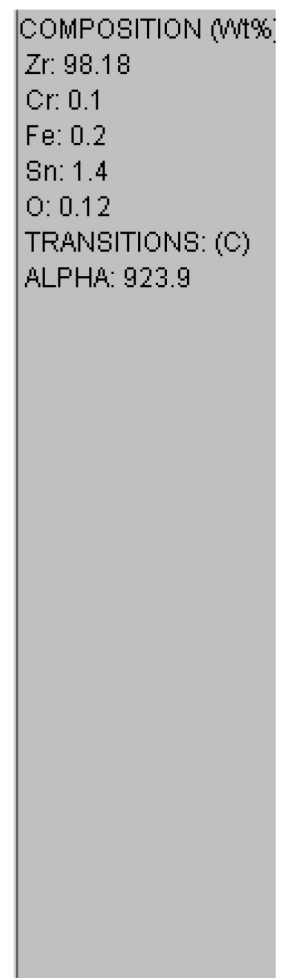

COMPOSITION (Nits)

Zr: 98.18

Cr: 0.1

Fe: 0.2

Sn: 1.4

0. 0.12

TRANSITIONS: (C)

ALPHA: 923.9

ALPHA GB(0.5\%)

ALPHA MATRIX(0.5\%)

$-1.0 \mathrm{CIS}$

$-0.1 \mathrm{cis}$

$-0.01 \mathrm{cls}$

$-0.001 \mathrm{cls}$

Figure 27. Preliminary computation of the TTT and CCT diagrams for Zircaloy-4 and various cooling paths. 


\begin{tabular}{|c|lll|}
\hline HEAT TREATMENT DEVELOPMENT FOR & Identifier: & PLN-5403 & \\
THE TREAT LEU FUEL & Revision: & 0 & \\
ZR-ALLOY CLADDING VIA & Effective Date: & $07 / 02 / 2018$ & Page: 32 of 33 \\
TIME-TEMPERATURE DIAGRAMS & & & \\
\hline
\end{tabular}

The computation of an integrals set of Time Temperature diagrams ( $\beta$-treatment, TTT and CCT) will allow for an informed selection of heat treatment that will impart the best properties to the Zircaloy-4 cladding material for the optimum performance during in service conditions and transient testing of the TREAT LEU fuel core.

Afterwards, the calculation of the TT diagrams, and a set of experiments can be performed for validation of the predicted microstructure. At the same time, an ordered compilation of the available technical literature will serve to gather all the available information to correlate the process-structure-properties for Zircaloy-4 and to visualize the present gaps on data availability. If possible, commercial partners could participate and also provide meaningful information that will help to reduce the need for testing. This way, testing can be focalized to certain areas of interest after the final selection of a cladding alloy has been done.

\section{REFERENCES}

1. "Upgraded TREAT Facility - Transient Reactor Test Facility (TREAT) Final Safety Analysis Report: Chapter 1 - Introduction and General Description of the Upgraded Transient Reactor Test Facility," S3942-0001-YT Rev. 8 11/12/14, p. 1-6 of 1-32.

2. "Upgraded TREAT Facility - Transient Reactor Test Facility (TREAT) Final Safety Analysis Report: Chapter 4 - Reactor," S3942-0001-YT Rev. 8 11/12/14, p. 162-163.

3. C.J. Parga “TREAT LEU Fuel Assembly Cladding Oxidation” PLN-5398, INL-MIS-16-40714, December 2017, 8-19.

4. J. Vandegrift, B. Jaques "Report on the oxidation and transient testing of zirconium alloys" INL/INT$18-45726,6 / 14 / 2018$, p. 1-55.

5. "Upgraded TREAT Facility - Transient Reactor Test Facility (TREAT) Final Safety Analysis Report: Chapter 15 - Accident Analyses," S3942-0001-YT Rev. 8 11/12/14, p. 28-31, 48-63.

6. W.D. Callister Jr., and D.G. Rethwisch, "Materials Science and Engineering: An Introduction," 8th ed., John Wiley and Sons Inc., 2010, pp. 219-229, 355-370.

7. D.E. Laughlin, K. Hono (Eds.), "Physical Metallurgy: Recovery and Recrystallization: Phenomena, Physics, Models, Simulation," $5^{\text {th }}$ Ed., Elsevier, 2014, p. 2291-2296.

8. G.F. Vander Voort (Ed.), "Atlas of Time-Temperature Diagrams for Iron and Steels," ASM International, 1991, p. 3-11.

9. R.T. Webster, "Zirconium and Hafnium, Properties and Selection: Nonferrous Alloys and Special-Purpose Materials," Vol 2, ASM Handbook, ASM International, 1990, p. 661-669.

10. C.J. Parga, "TREAT LEU Fuel Assembly Cladding Oxidation - Review and Test Plan," INL/MIS-16-40714, 02/21/2017.

11. G.F. Vander Voort (Ed.), “Atlas of Time-Temperature Diagrams for Nonferrous Alloys,” ASM International, 1991, p. 272-275, 448-454.

12. ASM International, "Mo (Molybdenum) Binary Alloy Phase Diagrams," Alloy Phase Diagrams, Vol 3, ASM Handbook, ASM International, 1992, p 2.292-2.298.

13. ASM International, "Fe (Iron) Binary Alloy Phase Diagrams," Alloy Phase Diagrams, Vol 3, ASM Handbook, ASM International, 1992, p 2.194-2.207. 


\begin{tabular}{|c|c|c|c|}
\hline $\begin{array}{c}\text { HEAT TREATMENT DEVELOPMENT FOR } \\
\text { THE TREAT LEU FUEL } \\
\text { ZR-ALLOY CLADDING VIA } \\
\text { TIME-TEMPERATURE DIAGRAMS }\end{array}$ & $\begin{array}{l}\text { Identifier: } \\
\text { Revision: } \\
\text { Effective Date: }\end{array}$ & $\begin{array}{l}\text { PLN-5403 } \\
0 \\
07 / 02 / 2018\end{array}$ & Page: 33 of 33 \\
\hline
\end{tabular}

14. ASM International, "Cr (Chromium) Binary Alloy Phase Diagrams," Alloy Phase Diagrams, Vol 3, ASM Handbook, ASM International, 1992, p 2.152-2.162.

15. A. Sarkar, K.L. Murty, "Microstructure-Mechanical Property Correlation of Cryo Rolled Zircaloy-4," Journal of Nuclear Materials 456, 2015, 287-291.

16. J.B. Bai, C. Prioul, and D. Francois, "Hydride Embrittlement in ZIRCALOY 4 Plate: Part I. Influence of Microstructure on the Hydride Embrittlement in ZIRCALOY 4 at $20^{\circ} \mathrm{C}$ and $350^{\circ} \mathrm{C}$," Metallurgical and Materials Transactions A, Vol. 25A, 1994.

17. S-H. Jung, and I-S Kim, "Effect of $\beta$-Heat Treatment on Microstructure and Mechanical Anisotropy of Zircaloy-4 Fuel Cladding," Journal of Nuclear Science and Technology, 26(5), 1989, pp. 516-524.

18. N.V. Bangaru, "An Investigation of the Microstructures of Heat-Treated Zircaloy-4," Journal of Nuclear Materials 131, 1985, p. 260-290.

19. Y.H. Jeong, K.S. Rheem, C.S. Choi, and Y.S. Kim, "Effect of Beta Heat Treatment on Microstructure and Nodular Corrosion of Zircaloy-4," Journal of Nuclear Science and Technology, 30(2), Feb. 1993, pp. 154-163. 